\title{
Differential Paired Pulse Depression of Non-NMDA and NMDA Currents in Pyramidal Cells of the Rat Frontal Cortex
}

\author{
Youngnam Kang \\ Department of Physiology, Faculty of Medicine, Kyoto University, Kyoto 606, Japan
}

Excitatory postsynaptic currents (EPSCs) were induced in layer II-V pyramidal cells in the frontal cortex of the young rat (postnatal day 14-21) by stimulation of layers II/III in the presence of bicuculline using the whole-cell patch-clamp technique. EPSCs usually consisted of fast and slow components that were sensitive to $C N Q X$ and APV, respectively. In response to paired stimuli of identical strength, paired pulse depression (PPD) was seen for these EPSCs. The PPD of fast EPSCs was most pronounced at an interstimulus interval (ISI) of 200-300 msec and ceased to occur at ISIs greater than 3-5 sec, while the PPD of slow EPSCs became most pronounced at an ISI of 500-1000 msec and ceased to occur at ISIs greater than $10 \mathrm{sec}$. The PPD of fast EPSCs was attenuated by (-)-baclofen (1-5 $\mu \mathrm{M})$ and removed by 2-hydroxy-saclofen (0.2-0.4 mM). By contrast, the PPD of slow EPSCs consisted of early and late components that were attenuated by $(-)$-baciofen and muscarine $(1-5 \mu \mathrm{M})$, respectively. The late PPD of slow EPSCs induced in the presence of baclofen was removed by pirenzepine (1-3 $\mu \mathrm{m})$. Thus, fast and slow components of glutamatergic EPSCs displayed two distinct PPDs. These results suggest that a part of the glutamatergic afferents likely arising from layer II/III pyramidal cells may terminate predominantly on NMDA receptors in pyramidal cells of the frontal cortex and receive distinct presynaptic inhibition through at least the muscarinic receptors.

[Key words: paired pulse depression, non-NMDA and NMDA currents, $G A B A_{B}$ receptors, muscarinic receptors, pyramidal cells, rat frontal cortex]

The paired pulse depression (PPD), in which the second response was smaller than the first in response to two stimuli of identical strength, was first reported in the monosynaptic inhibitory postsynaptic current (Davies et al., 1990). Since baclofen, a $\mathrm{GABA}_{\mathrm{B}}$ receptor agonist, attenuated the first response to the same size as that of the second response, and since saclofen or CGP 35384, a $\mathrm{GABA}_{\mathrm{B}}$ receptor antagonist, removed depression of the second response, the mechanism of PPD has been attributed to presynaptic inhibition arising from the activity of GA$\mathrm{BA}_{\mathrm{B}}$ autoreceptors on the presynaptic terminals of GABAergic

\footnotetext{
Received Apr. 25, 1995; revised Aug. 14, 1995; accepted Aug. 16, 1995.

This work was supported by Grants-in-Aid for General Scientific Research (C) 06680810 and 07680891 to Y.K. from the Japanese Ministry of Education, Science and Culture. I thank Prof. H. Ohmori and Drs. T. Araki and T. Hirano for critical reading of the manuscript.

Correspondence should be addressed to Youngnam Kang, Department of Physiology, Faculty of Medicine, Kyoto University, Sakyo-ku, Kyoto 606, Japan.

Copyright (C) 1995 Society for Neuroscience $\quad 0270-6474 / 95 / 158268-13 \$ 05.00 / 0$
}

fibers. It has also been reported that in dentate granule cells of the hippocampus, the degree of PPD of IPSC $\mathrm{B}_{\mathrm{B}}$ was significantly greater than that of IPSC $_{A}$ (Mott et al., 1993). This difference was attributed to the existence of separate $\mathrm{GABA}_{\mathrm{A}}$ and $\mathrm{GABA}_{\mathrm{B}}$ synapses (Otis and Mody, 1992; Sugita et al., 1992; Kang et al., 1994) or different affinities of $\mathrm{GABA}_{\mathrm{A}}$ and $\mathrm{GABA}_{\mathrm{B}}$ receptors for GABA (Bowery et al., 1987).

On the other hand, little is known about the PPD of excitatory postsynaptic events. There have been only a few studies that have demonstrated the PPD of EPSCs (Forsythe and Clements, 1990; Mori et al., 1994). It has been reported that in synaptic connections between cultured single hippocampal neurons, the PPD of glutamatergic EPSCs is mediated by the activity of presynaptic glutamate autoreceptors (Forsythe and Clements, 1990). However, muscarine, baclofen, and NPY have also been reported to play roles in the presynaptic inhibition of glutamatergic EPSCs evoked in CA1 pyramidal cells (Colmers et al., 1988; Sheridan and Sutor, 1990; Mack et al., 1993). Therefore, if the afferents containing $\mathrm{ACh}, \mathrm{GABA}$, and NPY were activated simultaneously with the glutamatergic afferents, not only the autoreceptor, but also the heterogeneous receptor on the preterminal would play a crucial role in inducing PPD of glutamatergic EPSCs. However, no study has demonstrated that the PPD of glutamatergic EPSCs is dependent on the activity of muscarinic, $\mathrm{GABA}_{\mathrm{B}}$ or NPY receptors, but is independent of the activity of autoreceptors. If the PPD of glutamatergic EPSCs was induced in pyramidal cells of rat frontal cortex, it would be of value to examine whether this PPD is mediated by the activity of autoreceptors or heterogeneous receptors, such as muscarinic, $\mathrm{GABA}_{\mathrm{B}}$ or NPY receptors. It would also be important to examine if there are any differences in the PPD between nonNMDA and NMDA EPSCs. Differential PPDs of non-NMDA and NMDA EPSCs would indicate a segregation of NMDA inputs from non-NMDA inputs. These questions were addressed in the present study.

The present study demonstrated that glutamatergic EPSCs displayed the PPD and that there was a significant difference in the time course, but not in the degree, of the PPD between nonNMDA and NMDA EPSCs. It was also found that the PPD of non-NMDA EPSCs was mediated by the activity of $\mathrm{GABA}_{\mathrm{B}}$ receptors, whereas that of NMDA EPSCs was mediated by the activity of both $\mathrm{GABA}_{\mathrm{B}}$ and muscarinic receptors.

\section{Materials and Methods}

Preparation. Sprague-Dawley rats (14-21 d postnatal) were deeply anesthetized with ether and decapitated. The brains were removed quickly and blocked with a razor blade to contain the frontal agranular cortex. Using a Microslicer (Dosaka, DSK-2000), slices of 150-200 $\mu \mathrm{m}$ thickness were cut coronally. The slices were incubated in oxygenated Ringer's solution for $1 \mathrm{hr}$ at room temperature. The standard Ringer's 
A .40
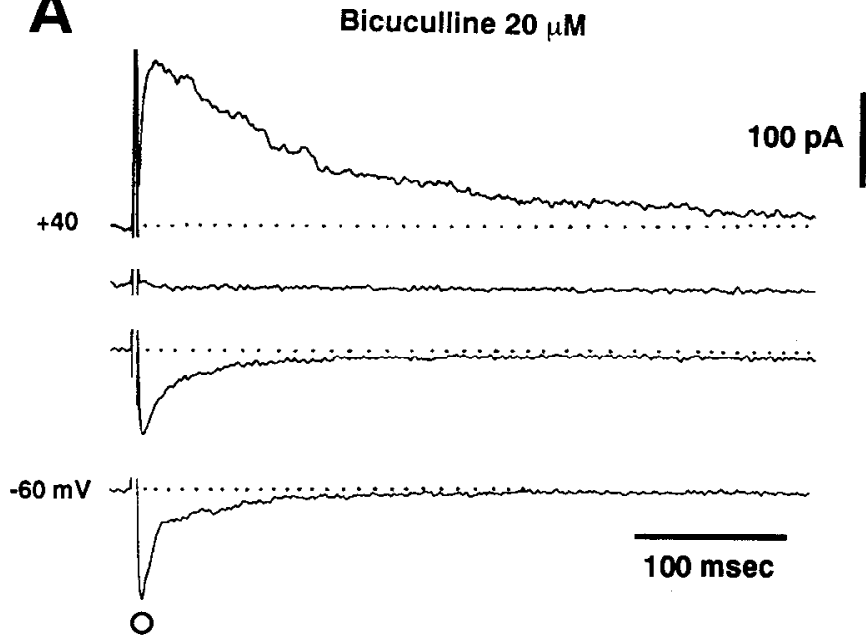

B

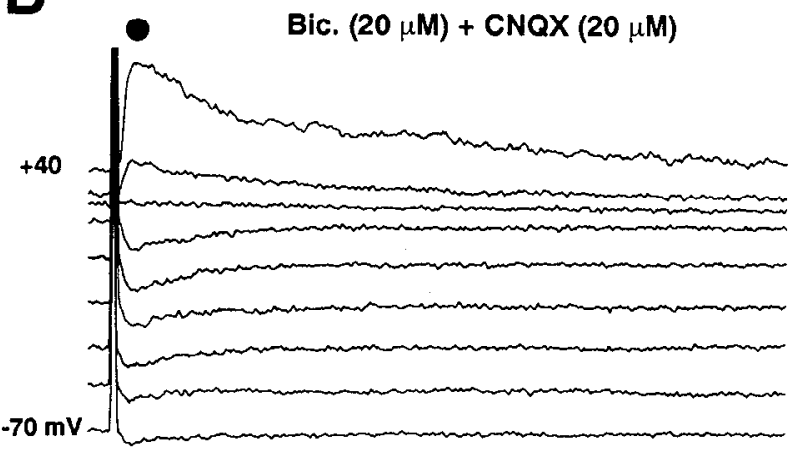

C

Bic. $(20 \mu M)+C N Q X(20 \mu M)+A P V(50 \mu M)$

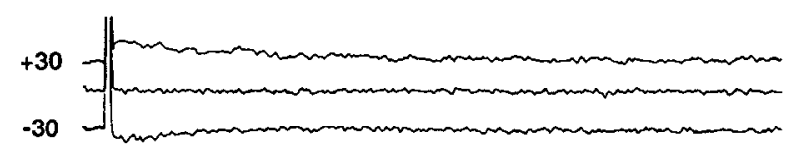

D

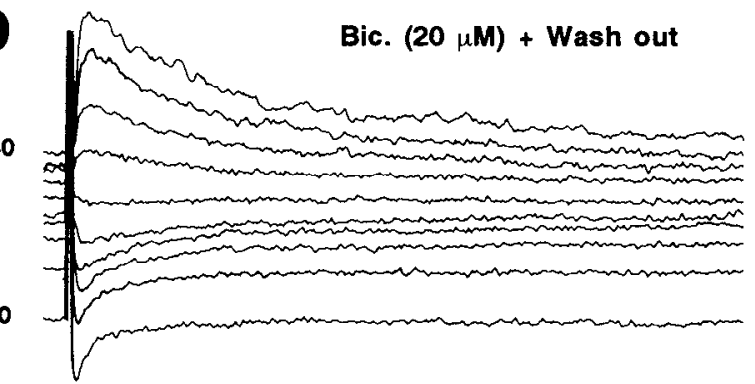

$\mathbf{E}$

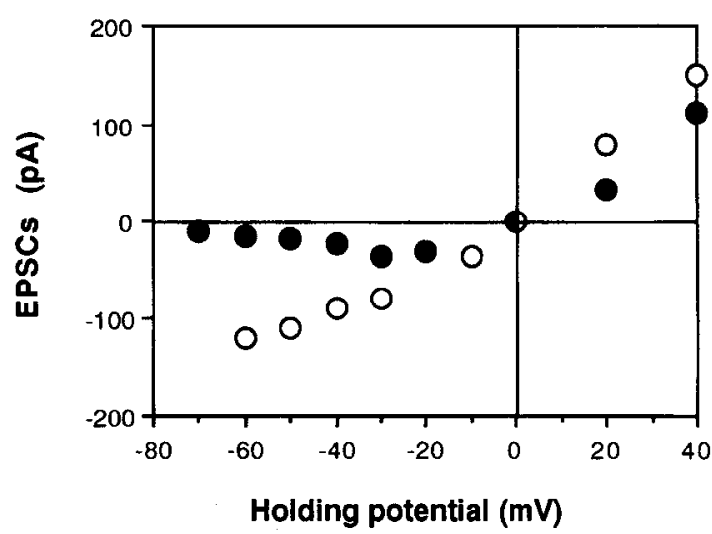

Figure 1. Fast and slow EPSCs. A, EPSCs induced at various holding potentials in a layer V pyramidal neurons in the presence of bicuculline $(20 \mu \mathrm{M}) . B$, CNQX $(20 \mu \mathrm{M})$ abolished fast EPSCs evoked at hyperpolarized holding potentials (e.g., $-60 \mathrm{mV})$, leaving slow EPSCs evoked at more depolarized holding potentials (e.g., $+40 \mathrm{mV})$. C, APV $(50 \mu \mathrm{M})$ abolished slow EPSCs, leaving almost no EPSC. $D$, Washout of CNQX and APV restored fast and slow EPSCs in the presence of bicuculline $(20 \mu \mathrm{M}) . E, I-V$ relationship for fast and slow EPSCs measured at the time indicated with open $(A)$ and solid circles $(B)$, respectively. Note the $J$-shaped $I-V$ relationship for slow EPSCs.

solution had the following composition (in $\mathrm{mM}$ ): $124 \mathrm{NaCl}, 1.8 \mathrm{KCl}$, $2.5 \mathrm{CaCl}_{2}, 1.3 \mathrm{MgCl}_{2}, 26 \mathrm{NaHCO}_{3}, 1.2 \mathrm{KH}_{2} \mathrm{PO}_{4}, 10$ glucose; and was continuously bubbled with a mixture of $95 \% \mathrm{O}_{2}-5 \% \mathrm{CO}_{2}$. After incubation, a single slice was transferred into a recording chamber (volume about $0.7 \mathrm{ml})$ placed on the fixed stage of an upright microscope (Nikon, Optiphoto-2) and was submerged in the superfusing medium at room temperature. Individual neurons were viewed with a water-immersion Nomarski optics (Nikon, 40×; working distance, $1.6 \mathrm{~mm}$ ). Whole-cell recordings were obtained from layers II-V cortical neurons that were pyramidal in shape and had stem parts of ascending apical dendrites.

Whole-cell recording. Patch pipettes were made from thin-walled borosilicated glass capillaries (Sutter; $1.5 \mathrm{~mm}$ o.d.) by pulling them in three steps (Sutter, P-87). The pipette had a DC resistance of 4-6 M $\Omega$ when filled with the standard pipette solution, which had the following ionic composition (in mM): $145 \mathrm{CsCl}, 3 \mathrm{MgCl}_{2}, 2 \mathrm{ATP}-\mathrm{Na}_{2}, 10 \mathrm{HEPES}$, 10 EGTA; pH 7.2 adjusted with $\mathrm{CsOH}$. Slices were usually bathed in the normal Ringer's solution described above.

Whole-cell currents were recorded with a patch-clamp amplifier (List, EPC-7). Membrane potentials were not corrected for the liquid-junction potential $(3 \mathrm{mV})$. The sealing resistance was usually more than $10 \mathrm{G} \Omega$. The series resistance was usually less than $15 \mathrm{M} \Omega$ and the recordings in which the series resistance was more than $20 \mathrm{M} \Omega$ were not included in the analysis. The series resistance was compensated by $50 \%$ when the amplitude of EPSCs was larger than $0.2 \mathrm{nA}$. Whole-cell current records were low-pass filtered at $10 \mathrm{kHz}$ (3-pole Bessel filter), digitized at a sampling rate of $10 \mathrm{KHz}$ (TEAC, RD-130TE), and stored on DATtape for later off-line analysis.

Stimulation and drugs. A monopolar tungsten stimulating electrode
(1-5 M $\Omega$ ) was used to induce EPSCs in pyramidal cells. Paired stimuli (PS; $0.1-0.2 \mathrm{msec}$ duration) of identical strength of less than $5 \mu \mathrm{A}$, separated by various interstimulus intervals, were applied at a frequency of $0.04-0.05 \mathrm{~Hz}$ to induce the first and second responses. The amplitude of the second response was measured from the tail of the response to the first stimulation alone. On the plane of cortical slices, the stimulating electrode was usually positioned at a site vertically above the tip of the recording pipettes by $100-200 \mu \mathrm{m}$ within layers II/III. EPSCs were induced in the presence of bicuculline in order to avoid the contamination of EPSCs by IPSCs. CNQX $(20 \mu \mathrm{M})$, APV $(50 \mu \mathrm{M})$, bicuculline $(20 \mu \mathrm{M}),(-)$-baclofen $(1-5 \mu \mathrm{M})$, 2-hydroxy-saclofen $(0.2-0.4 \mathrm{mM})$, muscarine $(1-5 \mu \mathrm{M})$, and pirenzepine $(1-3 \mu \mathrm{M})$ were administered via the perfusion medium. 6-cyano-7-nitroquinoxaline-2,3-dione (CNQX), DL-2-amino-5-phosphonovalerate (APV), and 2-hydroxy-saclofen were obtained from Tocris Neuramine. Bicuculline, muscarine, and pirenzepine were obtained from Sigma. Baclofen was a gift from Ciba-Geigy. Data given in the text are presented as means \pm SD, and statistical significance was assessed using the two-tailed $t$ test.

\section{Results}

Fast and slow components of EPSCs in pyramidal cells Whole-cell patch-clamp recordings were obtained from a total of 82 pyramidal cells of rat frontal cortex. In the presence of bicuculline $(20 \mu \mathrm{M})$, fast and slow components of EPSCs were usually induced in pyramidal cells by stimulation of layers II/III in the vicinity of recorded neuron as seen in Figure $1 A$. After adding CNQX in the extracellular medium containing bicucul- 
A

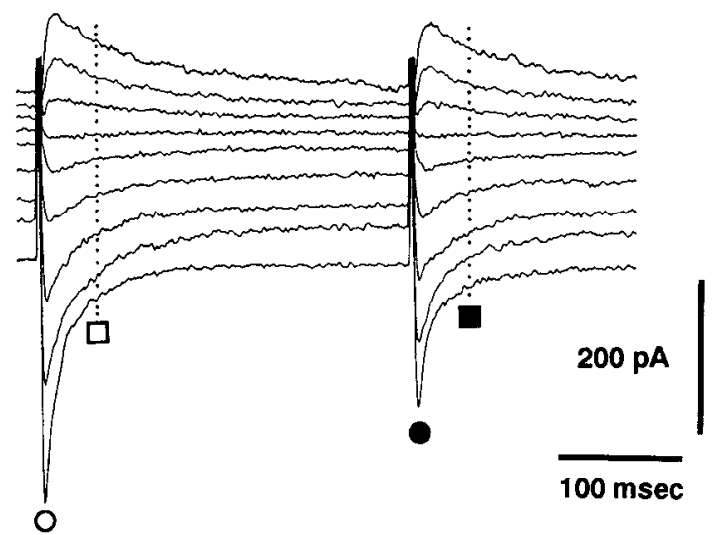

B

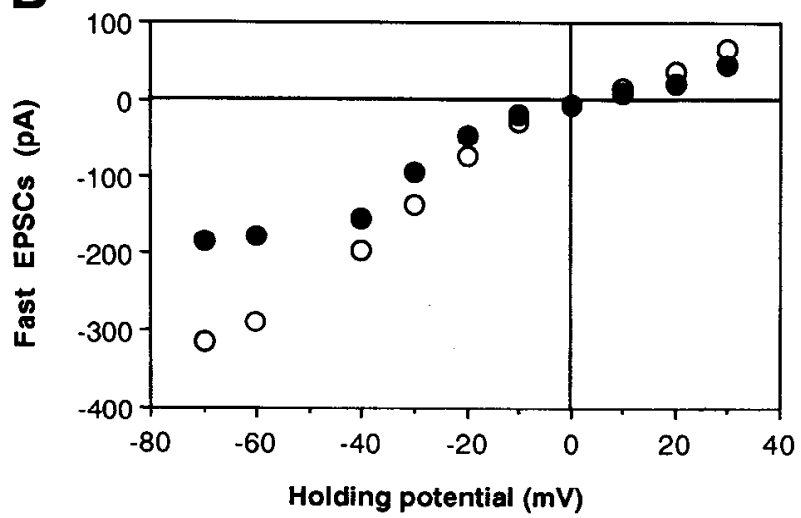

C

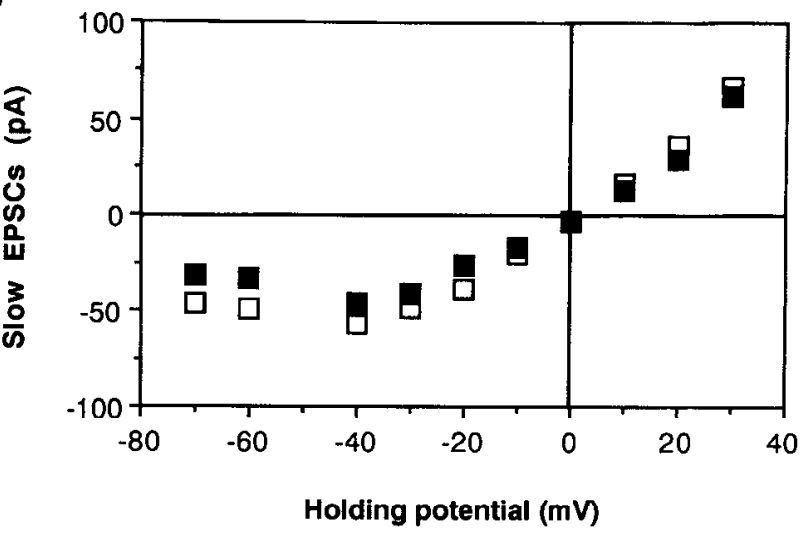

D

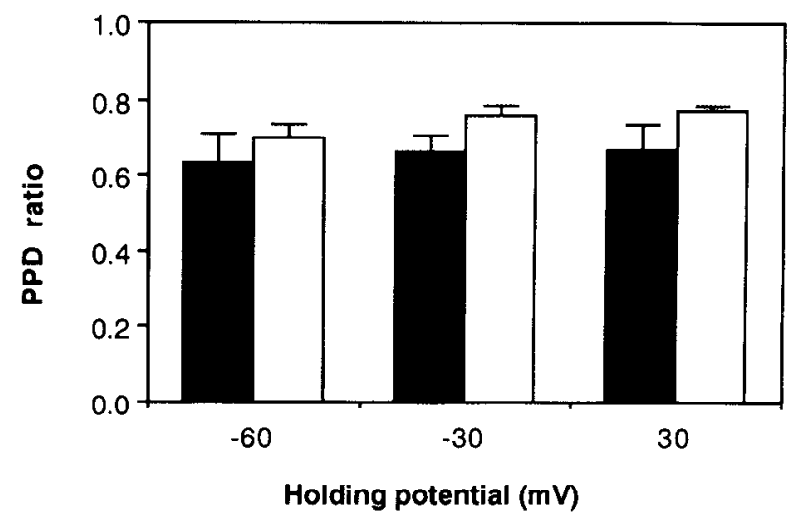

Figure 2. Differential PPD between fast and slow EPSCs. A, PPD of EPSCs induced by PS at 300 msec ISI at various holding potentials. Note a prominent PPD of fast EPSCs at hyperpolarized holding potentials (e.g., $-70 \mathrm{mV}$ ). $B, I-V$ relationships of the early components of the first and second responses measured at the time indicated with open and solid circles, respectively. $C, I-V$ relationships of the late components of the first and second responses measured at the time indicated with open and solid squares, respectively. $D$, Relationship between holding potential and the mean PPD ratio of the early (solid column) and late (open column) components obtained from five cells in response to 300 msec ISI. Error bars represent SD values. Note a larger degree of PPD of the early component than that of the late component, regardless of the holding potential. There was no significant difference $(p>0.2)$ in the PPD ratio among early components at the three different holding potentials, but the PPD ratio of late components at -30 and $+30 \mathrm{mV}$ was slightly larger than that at $-60 \mathrm{mV}(p<0.05)$. This may partly be due to the voltage-dependent involvement of NMDA currents in the late component.

line, fast EPSCs were abolished, but slow EPSCs remained (Fig. $1 B$ ). The slow EPSCs displayed the J-shaped current-voltage relationship characteristic to NMDA currents (solid circles in Fig. $1 E$ ). These slow EPSCs were completely and reversibly abolished by APV (Fig. 1C,D). The fast and slow EPSCs were, therefore, regarded as non-NMDA and NMDA currents, respectively. Thus, in pyramidal cells of the rat frontal cortex, EPSCs evoked by microstimulation of layer II/III were predominantly composed of non-NMDA and NMDA currents. The effects of paired stimuli (PS) were examined, in these EPSCs.

\section{Paired pulse depression of fast and slow EPSCs}

In response to $P S$ of identical strength with an interstimulus interval (ISI) of $300 \mathrm{msec}$ applied at various holding potentials, the second response was usually smaller than the first (Fig. $2 A$ ). The amplitudes of fast EPSCs (early components) of the first and second responses were measured at the timings indicated by open and solid circles in Figure 2, $A$ and $B$, respectively, and plotted against holding potentials. The $I-V$ relationship of the first early component was slightly inwardly rectified although that of the second component displayed a different pattern (open and solid circles, Fig. $2 B$ ). The amplitudes of EPSCs of the first and second responses measured at $50 \mathrm{msec}$ after the stimulus onset (late components), indicated by open and solid squares in Figure 2, $A$ and $C$, respectively, were also plotted against holding potentials. Since the $I-V$ relationships of both the first and second responses at this timing were similar to that of NMDA currents (Fig. $2 C$ ), the late component of EPSCs measured at this timing appcared to consist largely of slow EPSCs. The PPD ratio, which is a relative amplitude of the second to the first response, was calculated for the early and late components and was plotted against three different holding potentials of -60 , -30 , and $+30 \mathrm{mV}$ as indicated with solid and open columns, respectively, in Figure $2 D$. Regardless of the holding potential, at an ISI of $300 \mathrm{msec}$, the PPD ratio of the early component was invariably smaller than that of the late component in the five pyramidal cells tested. Although fast and slow EPSCs were not isolated pharmacologically, this observation raised the question of whether there are any differences in the PPD between fast and slow EPSCs. Therefore, the PPDs of fast and slow EPSCs were examined separately in response to PS with various ISIs. 
A
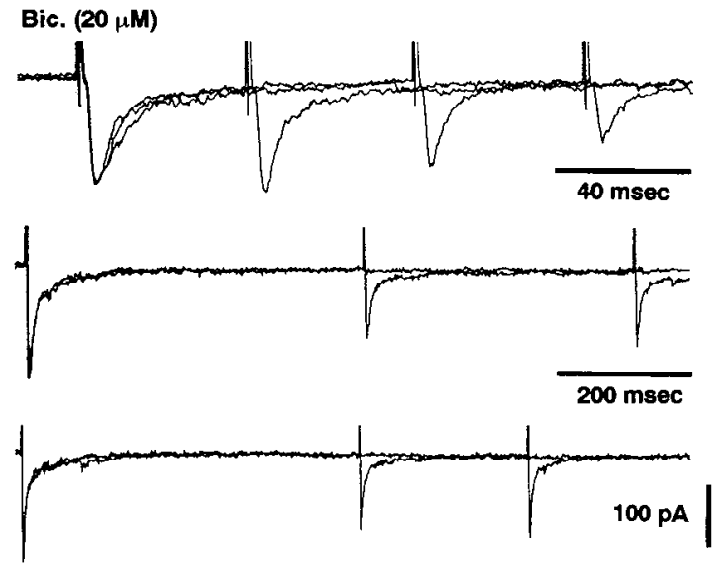

$400 \mathrm{msec}$

C

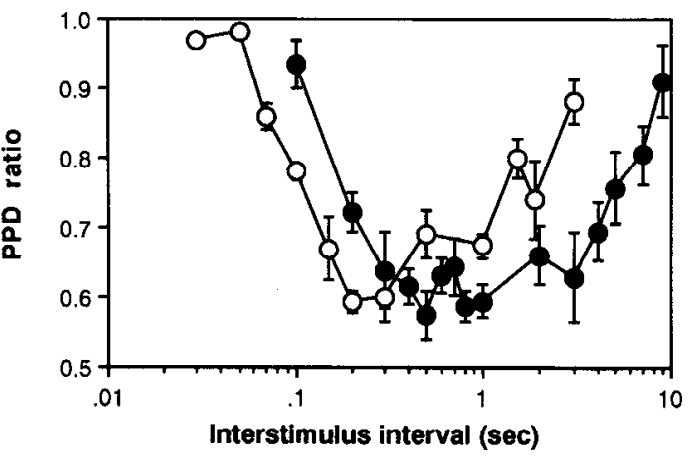

B

Bic. $(20 \mu M)+C N Q X(20 \mu M)$
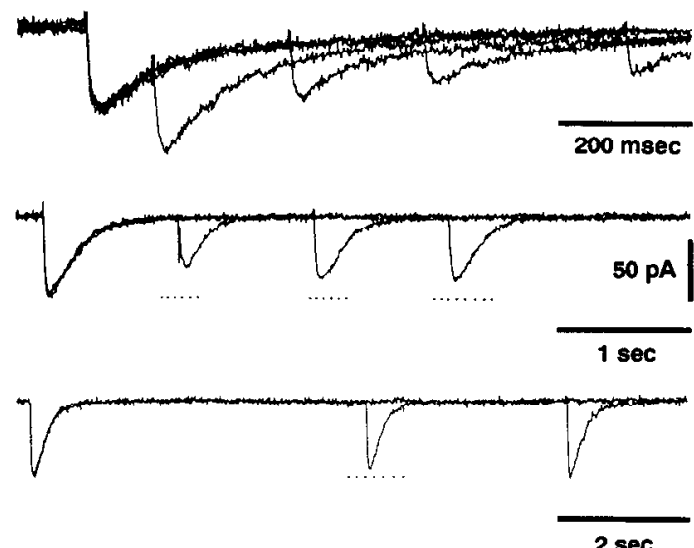

D

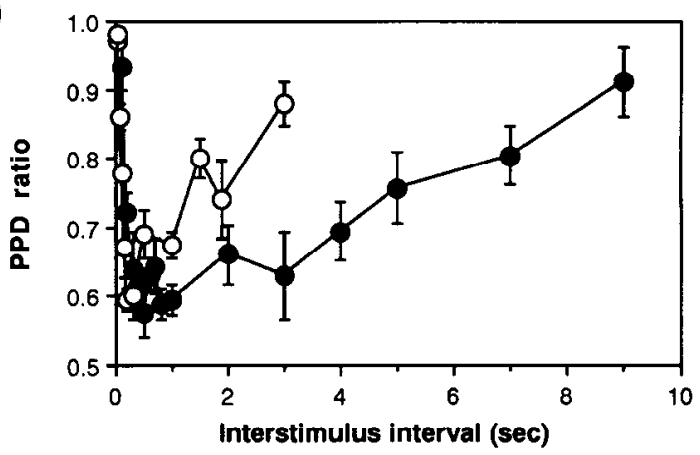

Figure 3. Temporal profile of PPDs of fast and slow EPSCs. A, Superimposed traces of the first and second responses of fast EPSCs induced at various ISIs at $-70 \mathrm{mV}$ in a pyramidal neuron in the presence of bicuculline. Note differences in the time scale in respective traces in $A$. $B$, Superimposed traces of the first and second responses of slow EPSCs induced at various ISIs at $-30 \mathrm{mV}$ in a pyramidal neuron in the presence of bicuculline $(20 \mu \mathrm{M})$ and CNQX $(20 \mu \mathrm{M})$. Note differences in the time scale in respective traces in $B$. Also note differences in the time scale between $A$ and $B$. C , plottings of mean PPDs of fast EPSCs (open circles) and slow EPSCs (solid circles) against ISIs with a logarithmic scale, obtained from five and six neurons, respectively. Error bars represent SEM values. D, plottings of mean PPDs of fast EPSCs (open circles) and slow EPSCs (solid circles) against ISIs with a normal scale. Error bars represent SEM values. Note a difference in the early phase of the temporal profile of the PPDs between fast and slow EPSCs in $C$ and also a difference in the late phase of the PPDs in $D$.

\section{Different time courses of PPDs of fast and slow EPSCS}

In response to PS with various ISIs, the temporal profile of the PPD of fast EPSCs was examined in the presence of bicuculline at a holding potential of $-70 \mathrm{mV}$, where slow EPSCs were very small and the peak amplitude of fast EPSCs was never affected by APV (see Figs. $1 A-C, 10 A_{b}, A_{c}$; Hestrin et al., 1990). The depression of the second response was maximal at ISIs of 200$300 \mathrm{msec}$ and ceased to occur at ISIs greater than 3-5 sec. As seen in Figure $3 A$, the peak amplitude of the first responses was fairly constant, but that of the second response was smaller than that of the first and varied depending on the ISI. There was no appreciable difference in the latency between the first and second responses (e.g., Figs. $3 A$, top trace; $4 A, B$ ). The latency of the second response varied very slightly from 2.6 to $2.8 \mathrm{msec}$. Usually, the range of changes in the latency of the second response was less than $0.3 \mathrm{msec}(n=5)$ in spite of large changes in the depression of the second response. The PPD ratio of fast EPSCs was plotted against the logarithm of the ISI (open circles, Fig. 3C). The PPD ratio started to decline at an ISI of $50 \mathrm{msec}$ and reached the minimum value $(0.59 \pm 0.03, n=5)$ at an ISI of $200 \mathrm{msec}$. Thereafter, the peak amplitude of the second response gradually returned to a size comparable to that of the first response at ISIs greater than $3-5 \mathrm{sec}$. A similar time course of the PPD was observed in five neurons tested (open circles, Fig. $3 C, D$ ).

The time course of the PPD of slow EPSCs, pharmacologically isolated from fast EPSCs in the presence of bicuculline and CNQX, was examined at a holding potential of $-30 \mathrm{mV}$. In response to PS with varying ISI, various PPDs of slow EPSCs were seen (Fig. $3 B$ ). The PPD ratio of -slow EPSCs was plotted against the logarithm of ISIs (solid circle, Fig. $3 C$ ). The PPD ratio started to decrease at an ISI of about $100 \mathrm{msec}$ and reached the minimum value $(0.57 \pm 0.08, n=6)$ at an ISI of $500 \mathrm{msec}$ (Fig. 3C). Thereatter, the amplitude of the second response gradually returned to a size comparable to that of the first response at ISIs of about $10 \mathrm{sec}$. A similar time course of the PPD of slow EPSCs was observed in a total of six neurons. At $200 \mathrm{msec}$ ISI, the PPD ratio of slow EPSCs $(0.72+0.06, n=6)$ was significantly larger $(p<0.01)$ than that of fast EPSCs $(0.59 \pm$ $0.03, n=5$ ) whereas at $3 \mathrm{sec}$ ISI, the PPD ratio of slow EPSCs $(0.63 \pm 0.12, n=6)$ was significantly smaller $(p<0.01)$ than that of fast EPSCs $(0.89 \pm 0.06, n=5)$. At $500 \mathrm{msec}$ ISI, the difference in the PPD ratio between fast and slow EPSCs was less significant $(p=0.03)$, although the PPD ratio of slow EPSCs $(0.57 \pm 0.08, n=6)$ was smaller than that of fast EPSCs $(0.69 \pm 0.07, n=5)$. Thus, both the onset and offset time in 
A Bic. $(20 \mu M)+A P V(50 \mu M)$

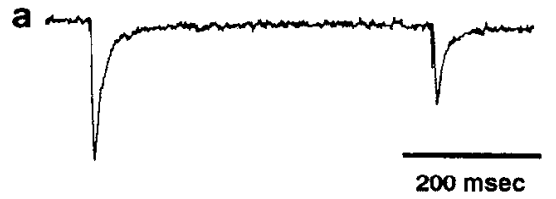

b
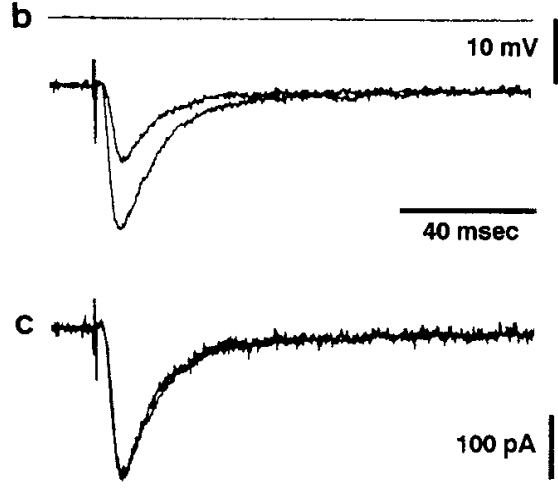

B Bic. $(20 \mu \mathrm{M})+$ APV $(50 \mu M)$
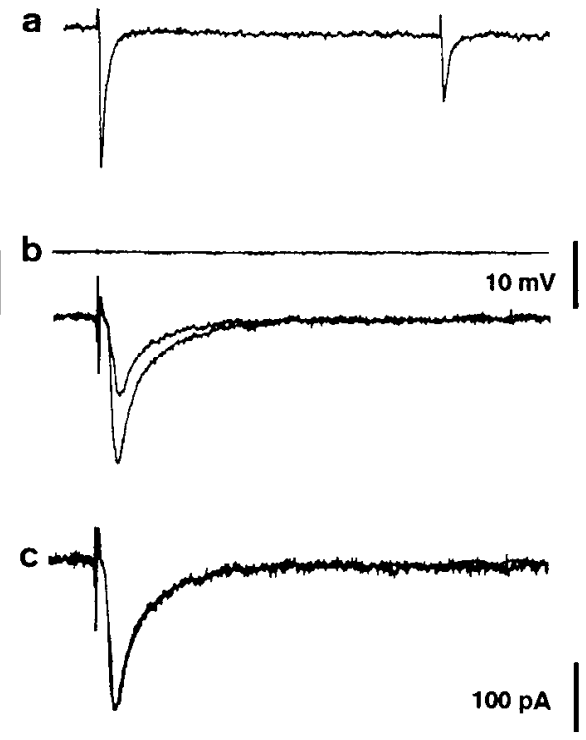

C Bic. $(20 \mu \mathrm{M})+\operatorname{CNQX}(20 \mu \mathrm{M})$

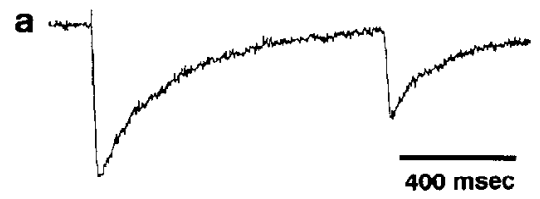

b

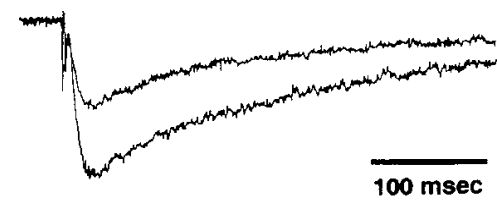

$100 \mathrm{msec}$

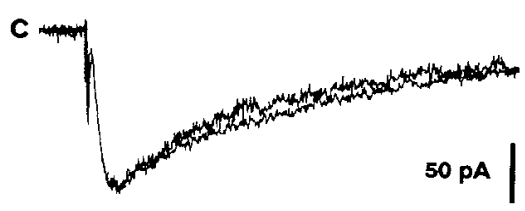

Figure 4. Nature of PPD. $A_{a}$ and $B_{a}$, PPDs of fast EPSCs, in two different pyramidal cells, at $0.5 \mathrm{sec}$ ISI at $-70 \mathrm{mV}$ in the presence of bicuculline $(20 \mu \mathrm{M})$ and APV $(50 \mu \mathrm{M})$. Time calibration in $A_{a}$ also applies in $B_{a} . A_{b}$ and $B_{b}$, The first and the second responses were superimposed. The upper traces show the superimposed voltage control records during PPD. There was no appreciable change in the voltage control record during the first and second responses. Voltage calibration in $A_{b}$ also applies in $C_{b}$ Time calibration in $A_{b}$ also applies in $A_{c}, B_{b}$, and $B_{c}$. $A_{c}$ and $B_{c}$, The second response was scaled to the same size as the first response and superimposed on the first response. Note a constant latency and a similar rising and decaying time courses. Also note a difference in the decay time course between $A$ and $B$. Current calibration in $A_{c}$ also applies in $A_{a}$ and $A_{b}$ and that in $B_{c}$ also applics in $B_{a}$ and $B_{b}$. $C_{a}$, PPD of slow EPSCs at $1 \mathrm{sec}$ ISI at $-30 \mathrm{mV}$ in the presence of bicuculline (20 $\mu \mathrm{M}$ ) and CNQX (20 $\mu \mathrm{M}$ ). $C_{b}$, Superimposed first and second responses. The upper traces are the superimposed voltage control records. $C_{c}$, The scaled second response to the same size as the first response was superimposed on the first response. Note a constant latency and a similar time course. Current calibration also applies in $C_{a}$ and $C_{b}$.

the temporal profile of the PPD of slow EPSCs were slower than those of fast EPSCs (Fig. $3 C, D$ ). This finding may point to a difference in the mechanism underlying the PPD of fast and slow EPSCs.

\section{The nature of PPD of fast and slow EPSCS}

In order to clarify the nature of the depression of the second response, the latency and the time courses of rise and decay of the second response were compared with those of the first response. In response to PS at $0.5 \mathrm{sec}$ ISI, the PPDs of fast EPSCs were induced in two different pyramidal cells at a holding potential of $-70 \mathrm{mV}$ (Fig. $4 A_{a} B_{a}$ ) and the PPD of slow EPSCs in another pyramidal cell at $-30 \mathrm{mV}$ in response to $1 \mathrm{sec}$ ISI (Fig. $4 C_{a}$ ). The second response was superimposed on the first response on a faster time scale (Fig. $4 A_{b}-C_{b}$ ). In Figure $4 A_{c}-C_{c}$, the second responses were scaled to the same size as those of the first responses and superimposed on the first responses. Thus, the latency and the time courses of rise and decay of the second response were almost the same as those of the first, in spite of the depression of the second response. In fast EPSCs induced in five cells at $-70 \mathrm{mV}$ by PS at $0.5 \mathrm{sec}$ ISI in the presence of APV and bicuculline, the latency $(2.9 \pm 0.3 \mathrm{msec})$, the time-topeak $(3.8 \pm 1.1 \mathrm{msec})$, and the half-width $(8.9 \pm 2.2 \mathrm{msec})$ of the second response were not signiticantly different from the latency $(2.8 \pm 0.3 \mathrm{msec})$, the time-to-peak $(4.0 \pm 1.1 \mathrm{msec})$, and the half-width $(9.2 \pm 2.8 \mathrm{msec})$ of the first response, respectively. Also in slow EPSCs induced in five cells at $-30 \mathrm{mV}$ by PS at 1 sec ISI in the presence of CNQX and bicuculline, the latency $(4.2 \pm 1.2 \mathrm{msec})$, the time-to-peak (16.3 \pm 8.6 $\mathrm{msec})$, and the half-width $(100 \pm 47 \mathrm{msec})$ of the second re- sponse were not significantly different from the latency $(4.0 \pm$ $1.2 \mathrm{msec})$, the time-to-peak $(16.9 \pm 8.8 \mathrm{msec})$, and the halfwidth $(107 \pm 50 \mathrm{msec})$ of the first response, respectively. If the depression of the second response was brought about by the failure of di- or polysynaptic transmission in response to PS, the latency, the time-to-peak, and the half-width of the second response would have been increased significantly depending on the degree of PPD.

\section{Effects of baclofen and saclofen on the PPD of fast EPSCs}

Baclofen, a $\mathrm{GABA}_{\mathrm{B}}$ receptor agonist, completely attenuated the PPD of fast EPSCs while saclofen, a $\mathrm{GABA}_{\mathrm{B}}$ receptor antagonist, removed the PPD. As seen in Figure 5A, a PPD of fast EPSCs was induced in response to PS with an ISI of $250 \mathrm{msec}$ applied at $-70 \mathrm{mV}$. Baclofen reversibly depressed the first response without depressing the second response until the amplitudes of the both responses became almost the same (Fig. 5A,B). Baclofen almost completely attenuated the PPD and increased the PPD ratio of fast EPSCs to more than 1.0 invariably in twelve neurons tested (Fig. $5 B, C$ ). These observations would indicate that the observed PPD is entirely mediated by the activity of $\mathrm{GABA}_{\mathrm{B}}$ receptors.

In contrast, saclofen increased the second response of fast EPSCs (Fig. 5D,E) and resulted in removal of the PPD of the fast EPSCs (Fig. $5 F$ ). As was the case in the previous study (Davies et al., 1990), the first response was slightly depressed probably due to the effect of saclofen as a partial agonist to GABA $_{B}$ receptors. Similar effects of saclofen on the PPD of fast EPSCs were obtained from three neurons in the presence of APV and bicuculline and from six neurons in the presence of 

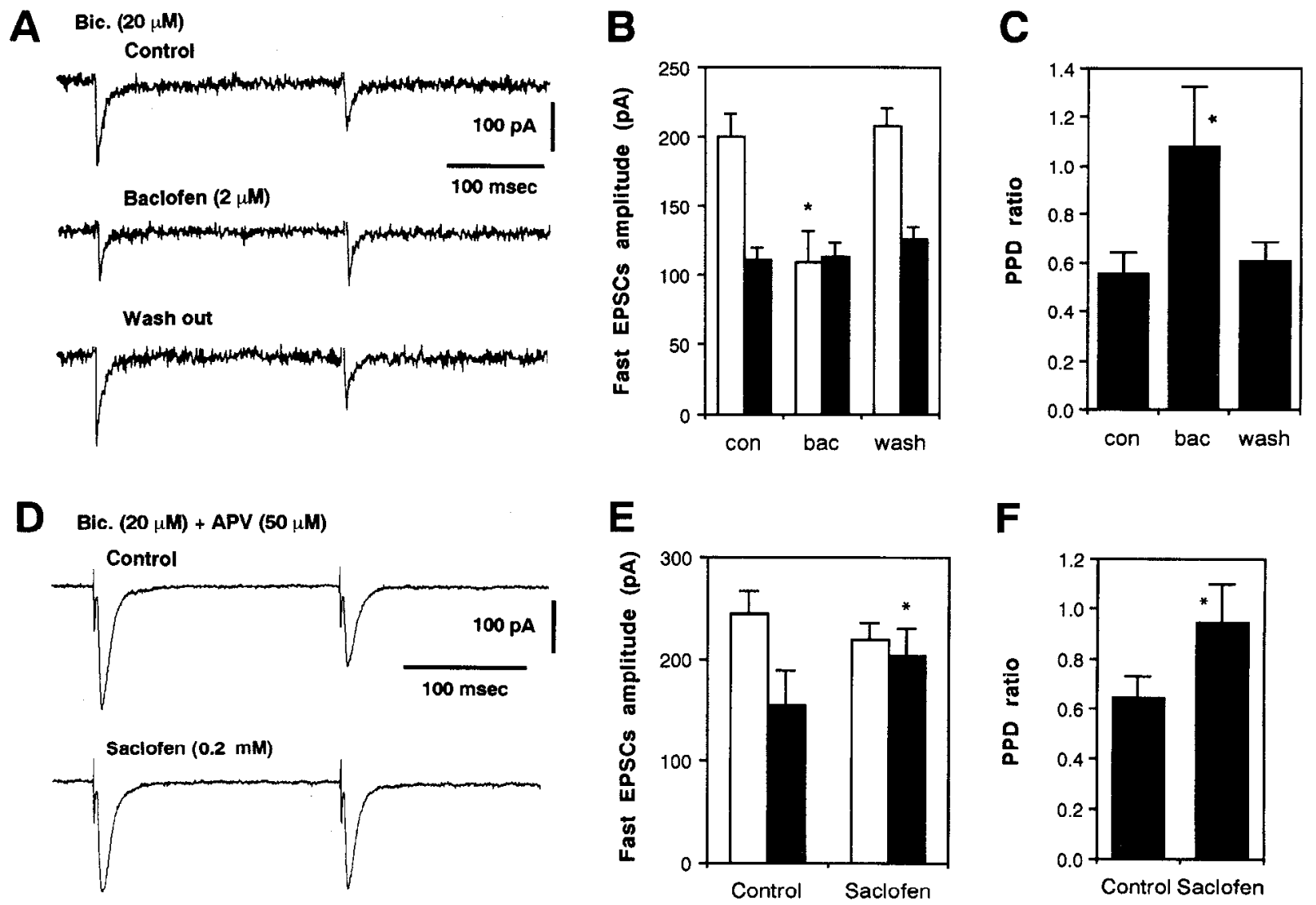

$\mathbf{F}$

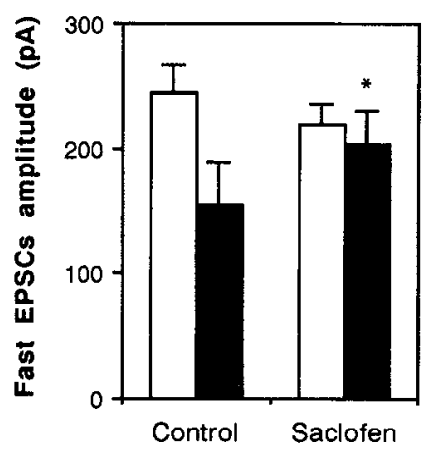

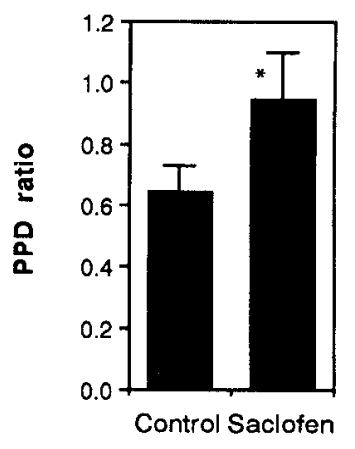

Figure 5. Effects of (-)-baclofen and saclofen on the PPD of fast EPSCs. A, PPDs of fast EPSCs at $250 \mathrm{msec}$ ISI at $-70 \mathrm{mV}$ in the presence of bicuculline. Each trace is the average of five trials for each condition. Baclofen $(2 \mu \mathrm{M})$ reduced the first response without reducing the second response. B, Open and solid columns represent the mean amplitude $( \pm \mathrm{SD}, n=5)$ of the first and second responses of fast EPSCs, respectively, for each condition. Baclofen significantly $\left(^{*}, p<0.001\right.$, two-tailed $t$ test) reduced the amplitude of the first response. $C$, the mean PPD ratio ( \pm SD, $n=5$ ) for each condition for the same cell. Note that baclofen significantly $(*, p<0.001)$ increased the PPD ratio. $D$, An averaged $(n=6)$ control record of the PPD of fast EPSCs at $200 \mathrm{msec}$ ISI at $-70 \mathrm{mV}$ in the presence of bicuculline $(20 \mu \mathrm{M})$ and APV (50 $\mu \mathrm{M})$. Saclofen (0.2 mM) increased the second response without marked effects on the first response. $E$, Open and solid columns represent the mean amplitude $( \pm \mathrm{SD}, n=$ 6 ) of the first and second responses of fast EPSCs for each condition, respectively. Saclofen significantly $\left({ }^{*}, p<0.01\right)$ increased the amplitude of the second response. $F$, The mean PPD ratio $( \pm \mathrm{SD}, n=6)$ for each condition for the same cell. Note that saclofen significantly $(*, p<0.01)$ increased the PPD ratio.

bicuculline alone. Although saclofen appeared to be less potent than baclofen, saclofen increased the PPD ratio of fast EPSCs evoked at $200 \mathrm{msec}$ ISI from $0.59 \pm 0.07$ to $0.86 \pm 0.12$ in the nine neurons. It was difficult to wash out saclofen, presumably because the effective concentration $(0.2-0.4 \mathrm{~mm})$ of saclofen was about 100 times higher than that of other drugs affecting the PPD in the present study. Since the PPD of fast EPSCs was completely attenuated by a $\mathrm{GABA}_{\mathrm{B}}$ agonist and largely removed by a GABA $A_{B}$ antagonist, the PPD of fast EPSCs may have been mediated by the activation of $\mathrm{GABA}_{B}$ receptors, which were probably located on the presynaptic terminal likely arising from glutamatergic neurons in layer II/III. The properties of the PPD of fast EPSCs were very similar to those of IPSCs in rat hippocampus reported previously (Davies et al., 1990).

Effects of baclofen on the PPDs of fast EPSCs evoked at various ISIs were also examined to see if there are any baclofeninsensitive components in the time course of the PPD of fast EPSCs. As shown in Figure $6 A_{a}$, the respective traces of the PPD response of fast EPSCs induced in response to PS with various ISIs in the presence of bicuculline and APV, were superimposed to show the PPD time course. A bath application of baclofen decreased the first response without any marked reductions in the second responses, as shown in Figure $6 A_{b}$. In Figure
$6 B$, the mean PPD ratio of fast EPSCs obtaincd beforc (open circles) and during (solid circles) application of baclofen in 4 cells were plotted against various ISIs. Baclofen almost completely attenuated the PPD at all ISIs examined. Thus, the whole time course of the PPD of fast EPSCs, obtained in the presence of APV and bicuculline, appeared to be baclofen sensitive.

\section{Effects of baclofen and muscarine on slow EPSCs}

The effects of baclofen on slow EPSCs were different from those on fast EPSCs. As seen in Figure 7A, PPDs of slow EPSCs at an ISI of $0.2 \mathrm{sec}$ were induced at $-30 \mathrm{mV}$ in the presence of CNQX and bicuculline. In contrast to fast EPSCs, not only the first response, but also the second response started to decrease after an application of baclofen. Consequently, both the first and second responses were decreased in amplitude significantly $(p$ $<0.01$, two tailed $t$ test) by baclofen although this resulted in a marked attenuation of the PPD of slow EPSCs (Fig. 7C). Baclofen increased the PPD ratio of slow EPSCs evoked at $0.2 \mathrm{sec}$ ISI from $0.65 \pm 0.09$ to $0.86 \pm 0.11$ in four neurons tested. If the observed PPD of slow EPSCs had been mediated entirely by the activity of $\mathrm{GABA}_{\mathrm{B}}$ receptors, the second response would not have been decreased until the amplitude of the first response reached the same level as that of the second response, similar 
Figure 6. Effccts of baclofen on PPDs of fast EPSCs at various ISIs. $A_{c}$, The first and second fast EPSCs obtained in response to PS at various ISIs were superimposed. Fast EPSCs were induced in the presence of bicuculline $(20 \mu \mathrm{M})$ and APV $(50 \mu \mathrm{M}) . A_{b}$, A bath application of baclofen $(5 \mu \mathrm{M})$ in the media containing bicuculline $(20 \mu \mathrm{M})$ and APV $(50 \mu \mathrm{M})$ decreased the amplitude of the first response with no marked changes in the second responses. $B$, The mean PPD ratio of fast EPSCs obtained in the presence of bicuculline $(20 \mu \mathrm{M})$ and APV $(50 \mu \mathrm{M})$ from four neurons before (open circle) and during applying baclofen (solid circle). Error bars represent SD values.
A

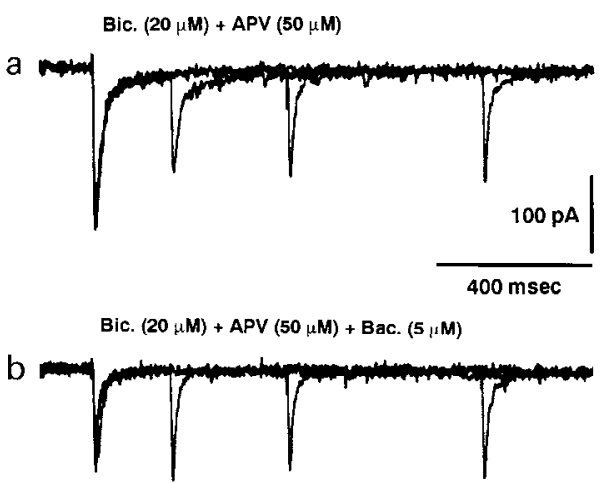

B

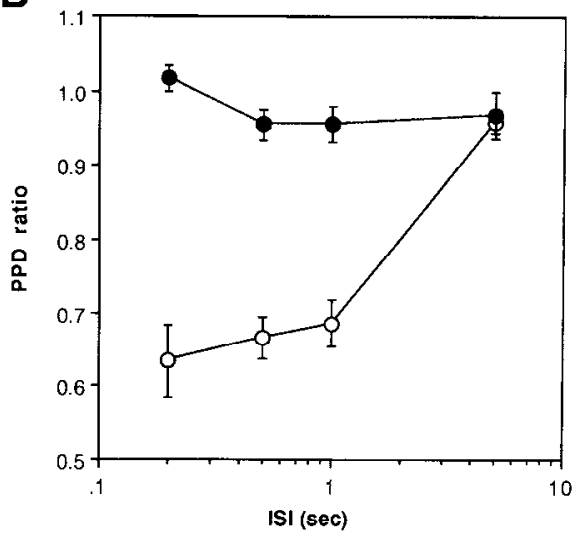

to the case with fast EPSCs. Therefore, the simultaneous reduction of the first and second responses may indicate an involvement of an additional component of the PPD of slow EPSCs. Alternatively, during the PPD of slow EPSCs, not all of the $\mathrm{GABA}_{\mathrm{B}}$ receptors may have been activated so that further de- pression of the second response could occur when baclofen was exogenously applied, although this was not the case for the PPD of fast EPSCs.

On the other hand, the PPD of slow EPSCs evoked at an ISI of $0.5 \mathrm{sec}$ was largely attenuated by muscarine. As shown in
A
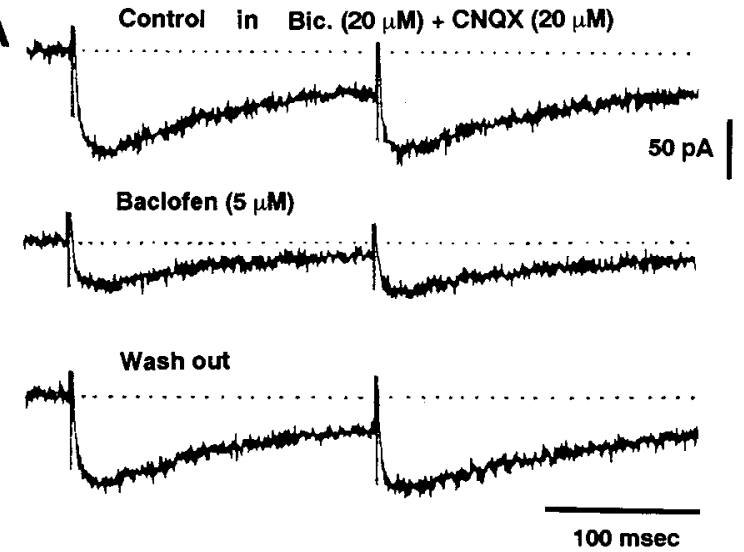

D
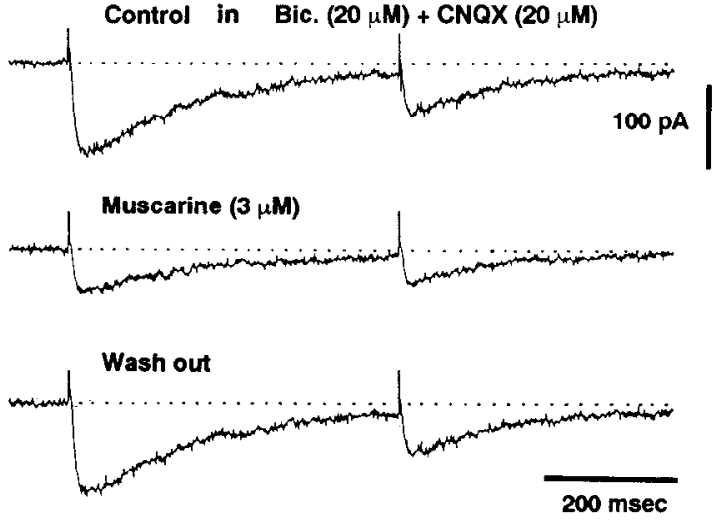

B
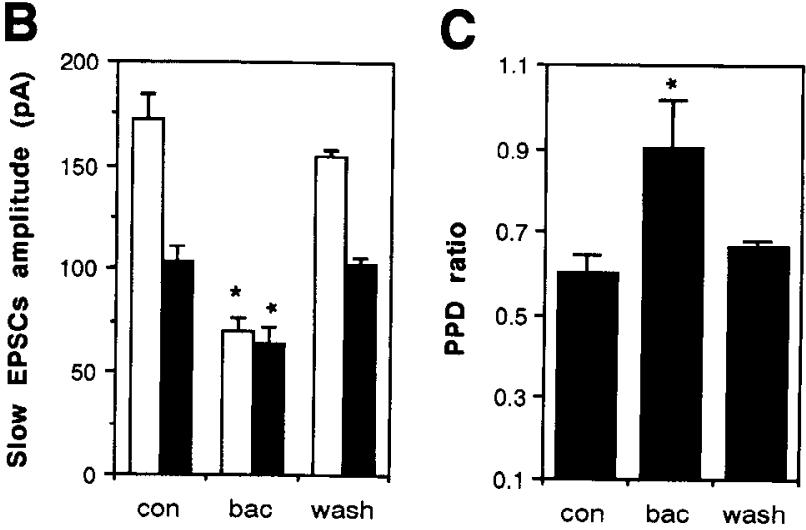

E

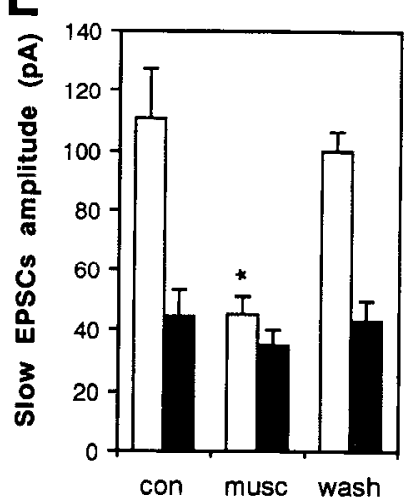

F

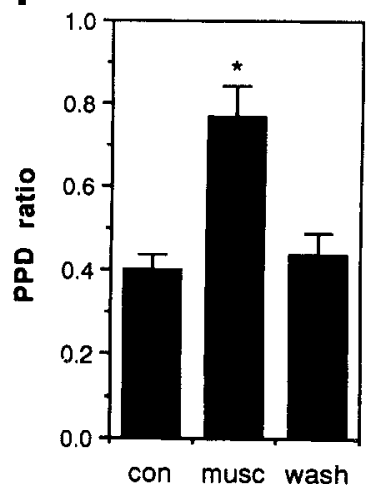

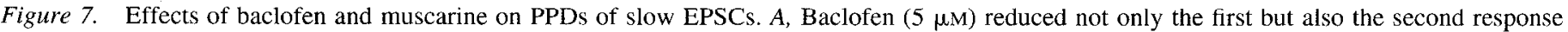

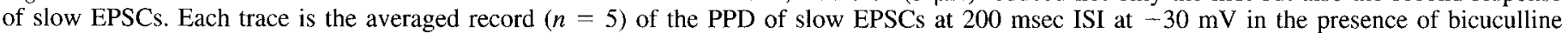

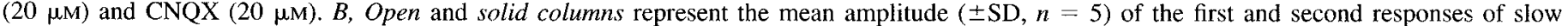

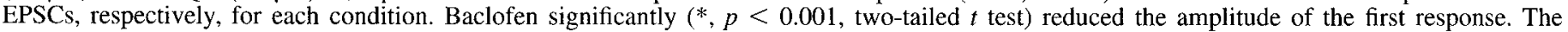

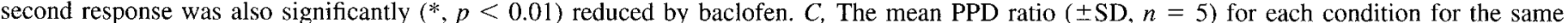

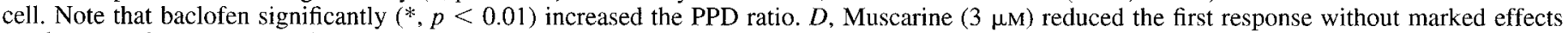

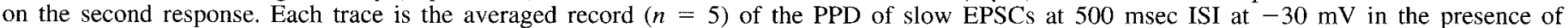

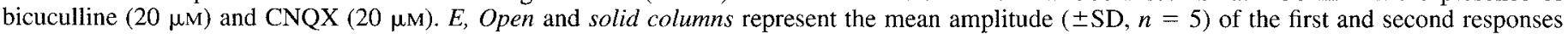

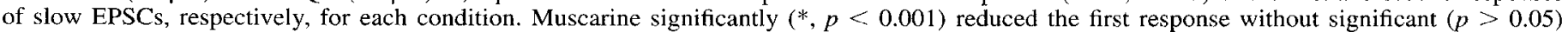

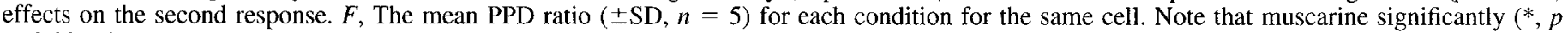
$<0.001$ ) increased the PPD ratio. 
A Bic. $(20 \mu \mathrm{M})+\operatorname{CNQX}(20 \mu \mathrm{M})$
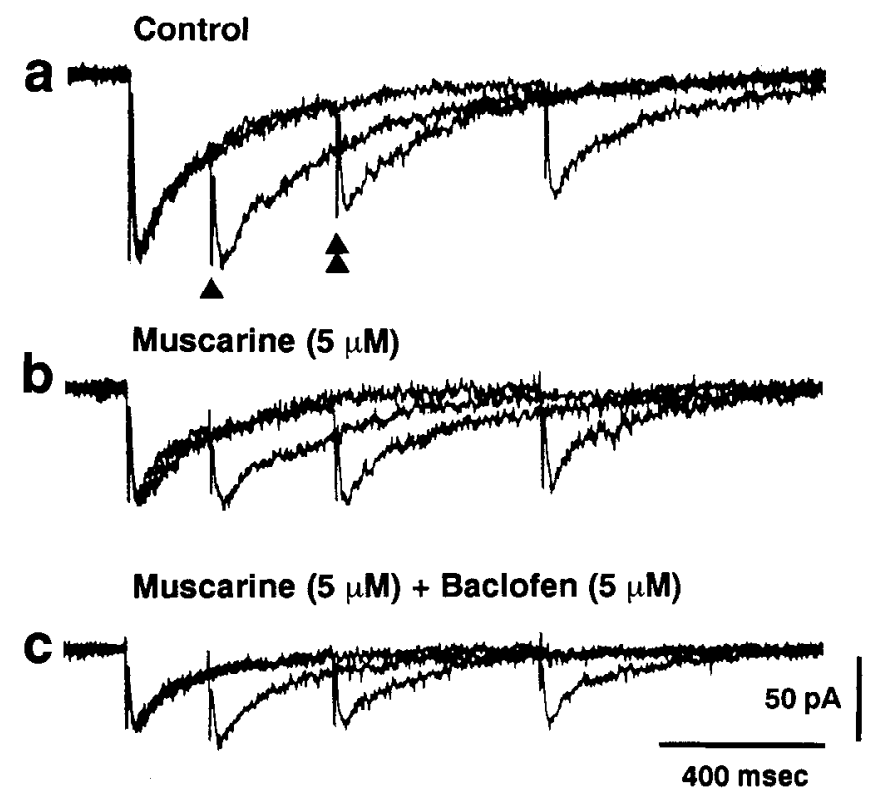

B

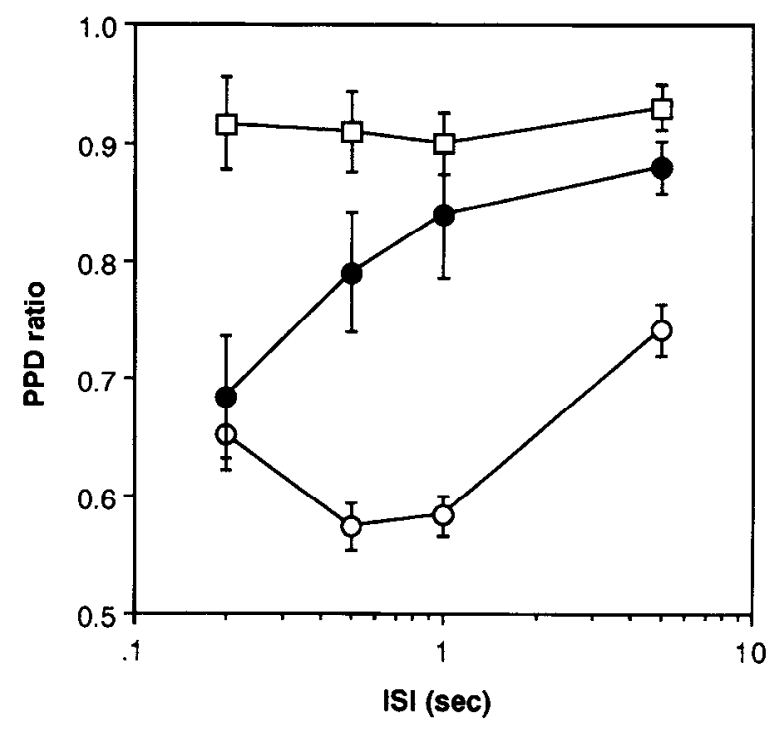

Figure 8. Early and late components of PPD of slow EPSCs. $A_{a}$, The respective averaged $(n=4)$ traces of the PPD at ISIs of $0.2($ arrowhead $)$, 0.5 (double arrowhead) and $1 \mathrm{sec}$ at $-30 \mathrm{mV}$ in the presence of bicuculline $(20 \mu \mathrm{M})$ and CNQX $(20 \mu \mathrm{M})$ were superimposed. $A_{b}$, Muscarine $(5$ $\mu \mathrm{M})$ reduced the first response without reducing the second response at 0.5 and $1 \mathrm{sec}$ ISIs markedly, resulted in a marked attenuation of PPD at 0.5 and $1 \mathrm{sec}$ ISI. In contrast, the second response at $0.2 \mathrm{sec}$ ISI was reduced by muscarine simultaneously with the first response, resulted in no marked attenuation of PPD at $0.2 \mathrm{sec}$ ISI. $A_{c}$, An addition of baclofen $(5 \mu \mathrm{M})$ in the presence of muscarine further reduced the first response without reducing the second response at $0.2 \mathrm{sec}$ ISI, resulted in a marked attenuation of PPD at $0.2 \mathrm{sec}$ ISI. In contrast, the second response at 0.5 and 1 sec ISIs were reduced as much as the first response. $B$, Plottings of PPD ratio against ISIs with a logarithmic scale. The mean PPDs obtained from four cells in the control condition, during muscarine and during muscarine and baclofen were represented by open circles, solid circles, and open squares, respectively. Error bars represent SD values. Note that the PPD of slow EPSCs is composed of early baclofen-sensitive and late muscarinesensitive PPD. Also note that the time course of muscarine-sensitive PPD is slower than that of baclofen-sensitive PPD.

Figure $7 D$, a PPD of slow EPSCs was evoked at an ISI of 0.5 $\mathrm{sec}$ at a holding potential of $-30 \mathrm{mV}$ in the presence of bicuculline and CNQX. A bath application of muscarine reversibly decreased the first response of slow EPSCs without marked effects on the second response (Fig. $7 D, E$ ). In contrast to the effect of baclofen on the PPD of slow EPSCs at $0.2 \mathrm{sec}$ ISI, muscarine did not decrease the second response at $0.5 \mathrm{sec}$ ISI significantly $(p>0.05$, two-tailed $t$ test), resulted in a marked attenuation of the PPD ratio (Fig. $7 E, F)$. Muscarine $(5 \mu \mathrm{M})$ increased the PPD ratio evoked at $0.5 \mathrm{sec}$ ISI from $0.56 \pm 0.12$ to $0.85 \pm 0.10$ in 10 cells tested. However, about $15 \%$ of the PPD evoked at 0.5 sec ISI still remained in the presence of muscarine $(5 \mu \mathrm{M})$. This would indicate that either the effect of muscarine on the PPD ratio was not saturated at the concentration used, or an additional component of the PPD of slow EPSCs that is independent of the activity of muscarinic receptors was present.

\section{Early and late components of the PPD of slow EPSCs}

Taking the effect of baclofen and muscarine on slow EPSCs into consideration, it can be predicted that the PPD of slow EPSCs may be composed of baclofen- and muscarine-sensitive components. Therefore, the effects of baclofen and muscarine were examined in the same neuron. As seen in Figure $8 A_{a}$, respective traces obtained in response to PS at various ISIs were superimposed in order to show changes in the respective second responses. Regardless of the constant amplitude of the first slow EPSCs, the amplitude of the second response varied in response to PS at ISIs of 0.2 (arrowhead in $A_{a}$ ), 0.5 (double arrowhead in $A_{a}$ ), 1 and $5 \mathrm{sec}$. As seen in Figure $8 A_{b}$, a bath application of muscarine largely decreased the first response without marked reduction in the second response of slow EPSCs evoked at ISIs longer than $0.5 \mathrm{sec}$ (double arrowhead in $A_{a}$ ). However, the second response evoked at an ISI of $0.2 \mathrm{sec}$ (arrowhead in $A_{a}$ ) was decreased simultaneously with the first response, leaving the PPD ratio at $0.2 \mathrm{sec}$ ISI almost unchanged (Fig. $8 A_{b}$ ). Consequently, only the late phase of the PPDs seen at ISIs longer than $0.5 \mathrm{sec}$ was attenuated markedly by muscarine (Fig. $8 B$, compare open and solid circles). The simultaneous reduction of the first and second responses at $0.2 \mathrm{sec}$ ISI is similar to that shown in Figure 7, $A$ and $B$. The unchanged PPD at $0.2 \mathrm{sec}$ ISI resulting from the simultaneous reduction would indicate the presence of muscarine-insensitive component in the early phase of the PPD. This muscarine-insensitive component of the PPD at $0.2 \mathrm{sec}$ ISI was largely sensitive to baclofen, as expected from the observations shown in Figure $7 A-C$. As shown in Figure $8, A_{c}$ and $B$ (compare the solid circle and open square), in the presence of muscarine, the addition of haclofen reduced the first response without reducing the second response evoked at $0.2 \mathrm{sec}$ ISI, resulted in a marked attenuation of the early phase of the PPD (compare Fig. $8 A_{b}, A_{c}$; see also Fig. $8 B$ ). In the absence of muscarine, baclofen did not markedly attenuate PPDs at ISIs longer than $0.5 \mathrm{sec}$, although the second response at these ISIs was also reduced simultaneously with the first response (figure not shown). Thus, the PPD of slow EPSCs appeared to consist of two distinct components; the baclofen-sensitive early component and the muscarine-sensitive late component (Fig. 8B). This may be the reason why the time course of the PPD of slow EPSCs was slower than that of fast EPSCs (see Fig. $3 C, D$ ). 
A

Bic. $(20 \mu M)+$ CNQX $(20 \mu M)+$ Baclofen $(5 \mu M)$

Control

Figure 9. Effects of pirenzepine on the late PPD of slow EPSCs. $A$. In the presence of baclofen ( $5 \mu \mathrm{M}), \mathrm{CNQX}$ $(20 \mu \mathrm{M})$ and bicuculline $(20 \mu \mathrm{M})$, effects of pirenzepine were examined on the PPD of slow EPSCs at $2 \mathrm{sec}$ ISI. Each trace is the averaged record $(n=$ 5) for control (a), during pirenzepine (b), and washout of pirenzepine $(c)$. $\mathrm{Pi}$ renzepine $(3 \mu \mathrm{M})$ increased the second response without marked effect on the first response. $B$, Open and solid columns represent the mean amplitude ( $\pm \mathrm{SD}, n=5$ ) of the first and second responses of slow EPSCs, respectively, for each condition. Pirenzepine significantly $(*, p<0.01$, two-tailed $t$ test $)$ increased the amplitude of the second response. $C$, The mean PPD ratio $( \pm \mathrm{SD}, n=5$ ) for each condition for the same cell. Note that pirenzepine significantly $(*, p<0.01)$ increased the PPD ratio.
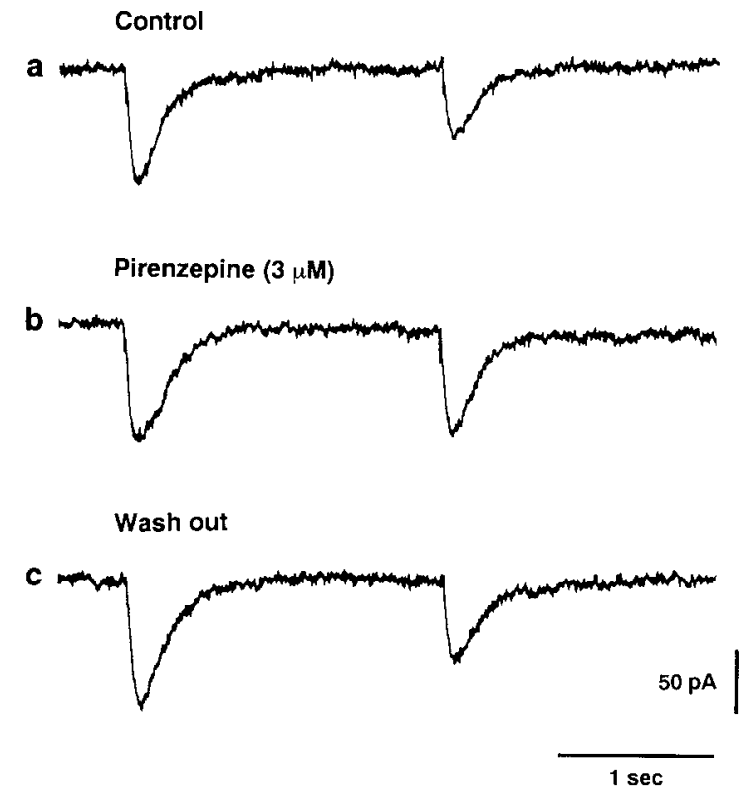
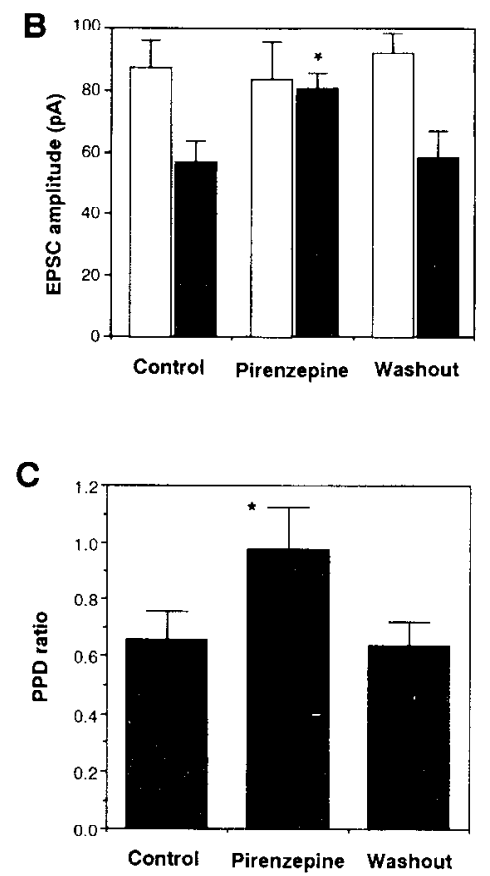

Baclofen $(5 \mu \mathrm{M})$ and muscarine $(5 \mu \mathrm{M})$ decreased the amplitude of slow EPSCs by $49.5 \pm 6.4 \%(n=5)$ and $50.4 \pm 3.4 \%$ $(n=7)$, respectively (e.g., Figs. 7-11). However, simultaneous application of baclofen and muscarine decreased the amplitude of slow EPSCs by $60-70 \%(n=3$; e.g., Fig. 8). It appears that the effects of baclofen and muscarine were not linearly summated, suggesting that in part, the depression caused by baclofen and muscarine may mutually occlude

In the presence of baclofen $(5 \mu \mathrm{M}), \mathrm{CNQX}$, and bicuculline, $32 \%$ PPD of slow EPSCs could still be produced in a pyramidal cell in response to PS at an ISI of $2 \mathrm{sec}$ (Fig. 9A). Under these conditions, pirenzepine almost completely removed the depression of the second response without marked effects on the first response, as seen in Figure $9, A$ and $B$. The PPD ratio was significantly ( $p<0.01$, two-tailed $t$ test) increased by applying pirenzepine (Fig. 9C). The PPD ratio of slow EPSCs at $1-2 \mathrm{sec}$ ISIs in the presence of baclofen was increased from $0.67 \pm 0.12$ to $0.96 \pm 0.17$ by pirenzepine in six pyramidal cells tested.

\section{Effects of muscarine on fast EPSCs}

Muscarine (1-5 $\mathrm{MM}$ ) easily attenuated the PPD of slow EPSCs in 10 out of eleven pyramidal neurons tested, but did not affect fast EPSCs markedly in six neurons tested. The effects of muscarine were examined on fast and slow EPSCs simultaneously in one and the same neuron for comparison. As seen in Figure 10, PPDs of fast and slow EPSCs were observed in response to PS at $0.5 \mathrm{sec}$ ISI at a holding potential of -60 (Fig. I $\left(2 A_{a}\right)$ and $-30 \mathrm{mV}$ (Fig. $10 B_{a}$ ), respectively. A bath application of muscarine decreased the peak amplitude of the first response by $28.5 \%$ when examined at $-30 \mathrm{mV}$ (Fig. $10 B_{b}$ ), but decreased that of the first one by only $6 \%$ when examined at $-60 \mathrm{mV}$ (Fig. $10 A_{b}$ ). This would indicate that slow EPSCs were more sensitive to muscarine than fast EPSCs were. This notion was further confirmed by the following observation. Adding APV in addition to bicuculline and muscarine almost completely abolished slow EPSCs, leaving only the fast EPSCs (Fig. 10 $A_{o}, B_{c}$ ) without any appreciable changes in the peak amplitude of the first and second fast FPSCs at -60$) \mathrm{mV}$ (compare Fig. 10 $A_{i,} A_{c}$ ). The degree of PPD of fast EPSCs was not affected appreciably by APV. As seen in Figure 10B, fast EPSCs evoked at $-30 \mathrm{mV}$ returned to the base line almost completely at the time indicated with an upward arrow. Therefore, EPSCs evoked at $-30 \mathrm{mV}$ and measured at this timing, as indicated with horizontal arrows in Figure 10, $B_{a}$ and $B_{b}$, appeared to consist largely of APVsensitive slow components. Consequently, it follows that the APV-sensitive slow component was depressed by about $32 \%$, whereas the peak amplitude of APV-insensitive fast EPSCs was depressed by only $6 \%$. Thus, slow EPSCs were much more sensitive to muscarine than fast EPSCs were. Although the first and second fast EPSC's were slightly depressed by muscarine by 5.4 $\pm 6.4 \%$ and $7.4 \pm 7.5 \%$, respectively (Fig. $10 C_{a}$ ), the PPD ratio of fast EPSCs at $0.5 \mathrm{sec}$ ISI was not affected significantly $(p>$ $0.1)$ in six cells tested both in the presence of bicuculline alonc $(n=3)$ and in the presence of APV and bicuculline $(n=3)$, as seen in Figure $10 C_{b}$. Similarly, the PPD ratio of fast EPSCs at $0.2 \mathrm{sec}$ ISI was not affected significantly $(p>0.1)$ by muscarine in 4 cells tested in the presence of bicuculline alone $(n=2)$ and in the presence of APV and bicuculline $(n=2)$. Therefore, it is not likely that the PPD of fast EPSCs involves the activation of muscarinic receptors. By contrast, baclofen largely depressed these muscarine-insensitive fast EPSCs and attenuated the PPD completely (Fig. 10A ). On the other hand, it was also examined whether or not glutamatergic fibers are sensitive to glutamate, and it was found that PPDs of fast and slow EPSCs were not appreciably attenuated by glutamate $(5-10 \mu \mathrm{M} ; n=6)$.

\section{Paired pulse facilitation and depression}

As shown in Figure 8, the PPD of slow EPSCs usually consisted of early baclofen-sensitive and late muscarine-sensitive components. However, in 8 of 39 pyramidal neurons, the early phase of the PPD of slow EPSCs was less prominent than the late phase of the PPD. As seen in Figure $11, A_{a}$ and $A_{c}$, the PPD at $0.2 \mathrm{sec}$ ISI was not prominent in a pyramidal neuron, though the PPD was scen at ISIs larger than $0.5 \mathrm{sec}$. A bath application 
A

a Bic. $(20 \mu \mathrm{M})$

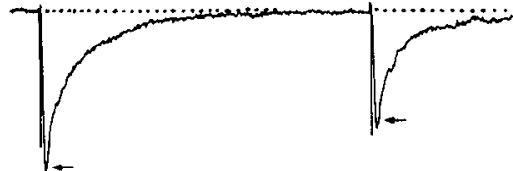

b Bic. $(20 \mu \mathrm{M})+$ Musc. $(5 \mu M)$

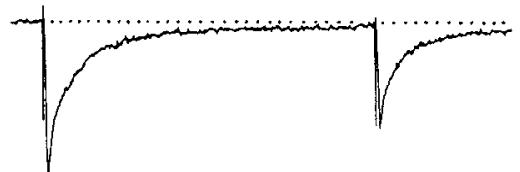

C Bic. $(20 \mu \mathrm{M})+$ Musc. $(5 \mu \mathrm{M})+$ APV $(50 \mu \mathrm{M})$

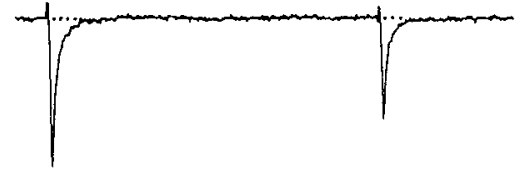

d Bic. $(20 \mu M)+A P V(50 \mu M)+$ Bac. $(5 \mu M)$

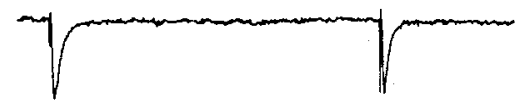

B

a Bic. $(20 \mu \mathrm{M})$

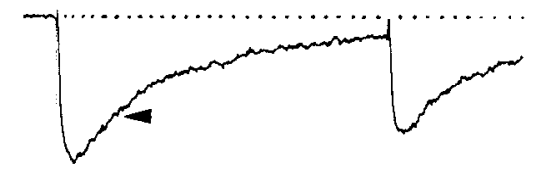

b BIC. $(20 \mu \mathrm{M})+$ Musc. $(5 \mu \mathrm{M})$

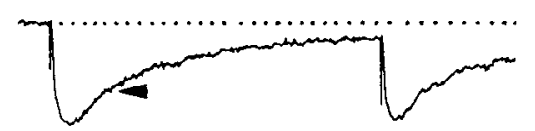

C Bic. $(20 \mu M)+$ Musc. $(5 \mu M)+$ APV $(50 \mu M)$

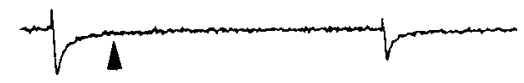

C

a

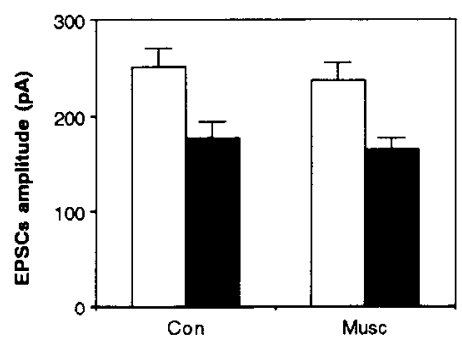

b

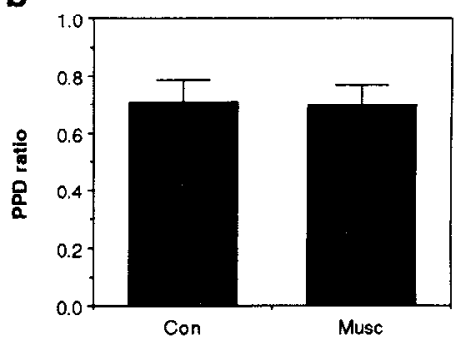

Figure 10. Effects of muscarine on PPD of fast EPSCs. $A_{a}$ and $B_{a}$, PPDs of fast and slow EPSCs induced in one and the same pyramidal cell at $0.5 \mathrm{sec}$ ISI at -60 and $-30 \mathrm{mV}$, respectively, in the presence of bicuculline $(20 \mu \mathrm{M})$. Horizontal arrows in $A_{a}$ indicate the peak levels of the first and second responses in $A_{b}$ obtained during applying muscarine. $A_{b}$ and $B_{b}$, A bath application of muscarine $(5 \mu \mathrm{M})$ largely reduced the first response at $-30 \mathrm{mV}$ but not at $-60 \mathrm{mV}$. $A_{c}$ and $B_{c}$, An addition of APV $(50 \mu \mathrm{M})$ in the media containing bicuculline $(20 \mu \mathrm{M})$ and muscarine $(5 \mu \mathrm{M})$ abolished slow EPSCs, leaving fast EPSCs alone. An upward arrowhead in $B_{c}$ indicates the timing when fast EPSCs returned to the base line almost completely. EPSCs measured at this timing (indicated with horizontal arrowheads) in $R_{u}$ and $B_{b}$ are largely composed of slow EPSCs. In spite of a large attenuation of slow EPSCs at $-30 \mathrm{mV}$ by muscarine (compare the level of the horizontal arrowheads in $B_{a}$ and $B_{b}$ ), the peak amplitude of the fast EPSCs at $-60 \mathrm{mV}$ remained almost constant. $A_{d}$, After washing out of muscarine, baclofen $(5 \mu \mathrm{M})$ attenuated PPD of fast EPSCs by depressing the first response. $C_{a}$, Opon and solid columns represent the mean amplitude $( \pm \mathrm{SD}, n-5)$ of the first and second responses of fast EPSCs at $-60 \mathrm{mV}$, respectively, for each condition. There were slight differences $(p<0.05)$ in the amplitudes of the first and second responses before and during application of muscarine. $C_{b}$, The mean PPD ratio of fast EPSCs at -60 to $-70 \mathrm{mV}$ for each condition from six cells, either in the presence of APV and bicuculline $(n-3)$ or in the presence of bicuculline alone $(n=3)$. Note no significant $(p>0.1)$ difference in the PPD ratio of fast EPSCs between each condition.

of baclofen decreased the first and second responses, but increased the PPD ratio at ISIs shorter than about $3 \mathrm{sec}$, disclosing the presence of a paired pulse facilitation (PPF) at ISIs shorter than about $0.5-1 \mathrm{sec}$ (Fig. $11 A_{b}, A_{c}$ ). The PPF may have masked the early phase of the PPD of slow EPSCs. Similar effects of baclofen on the less prominent PPD of slow EPSCs at short ISIs were observed in three neurons, although the degree of PPF varied.

In another pyramidal neuron, fast EPSCs displayed a prominent PPD at $0.5 \mathrm{sec}$ ISI, whereas the PPD of slow EPSCs was not prominent at the same ISI in the same neuron. As seen in Figure $11 B_{a}$, a prominent PPD of fast EPSCs was evoked by applying PS with $0.5 \mathrm{sec}$ ISI at $-70 \mathrm{mV}$. In the same neuron, when PS were applied at $-30 \mathrm{mV}$ in the presence of CNQX, the second response of slow EPSCs was not smaller, but in contrast, was slightly larger than the first response (Fig. 11 $B_{b l}$ ). Even in such cases, muscarine depressed the first response without decreasing the second response (Fig. $11 B_{b 2}$ ), as was the case in the PPD of slow EPSCs shown in Figures 7, 8, and 10. On the other hand, pirenzepine enhanced the second response without marked changes in the first response (Fig. $11 B_{b 4}$ ), as was the case in the PPD of slow EPSCs shown in Figure 9. Therefore, it was considered that the PPD at $0.5 \mathrm{sec}$ ISI was present, but masked by the PPF of slow EPSCs. A similar PPF at $0.5 \mathrm{sec}$ ISI was observed by applying either muscarine or pirenzepine in a total of five pyramidal neurons. Thus, the early phase of the PPD of slow EPSCs was occasionally masked by the PPF. This implies that facilitation and depression are not mutually exclusive and may be controlled independently. Since fast and slow EPSCs often behaved independently in response to PS, it appears that fast and slow EPSCs are separately modified.

\section{Discussion}

\section{Differential PPD between fast and slow EPSCs}

In the present study, the PPD of EPSCs was induced in layer II-V pyramidal cells of the rat frontal cortex in response to PS applied at layer II/III in the vicinity $(100-200 \mu \mathrm{m})$ of the recorded neuron. Fast and slow EPSCs were clearly distinguished in terms of the PPD. First, the time course of the PPD of slow EPSCs was slower than that of fast EPSCs. Second, the PPD of fast EPSCs was completely attenuated by baclofen and removed by saclofen, whereas the PPD of slow EPSCs was largely attenuated by baclofen and muscarine, and removed by pirenzepine in the presence of baclofen. The PPD of slow EPSCs consisted 
A
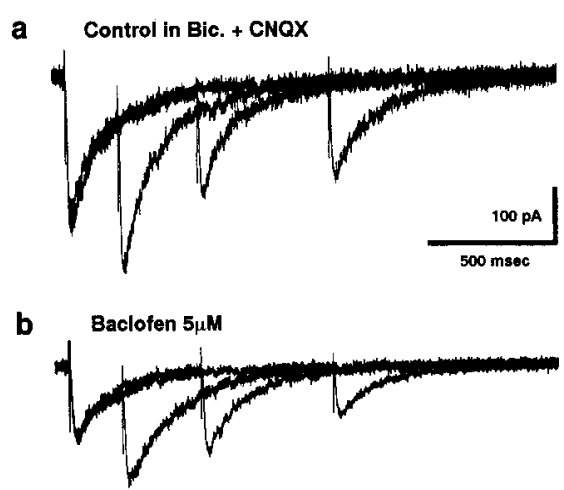

C

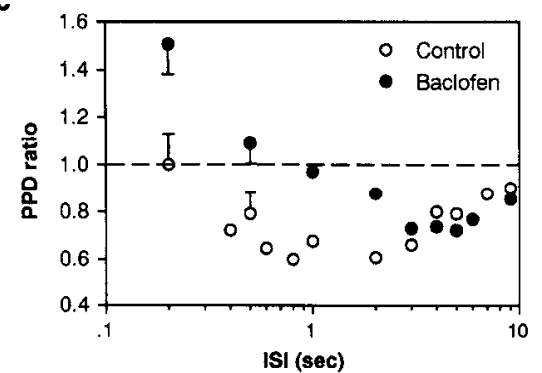

B
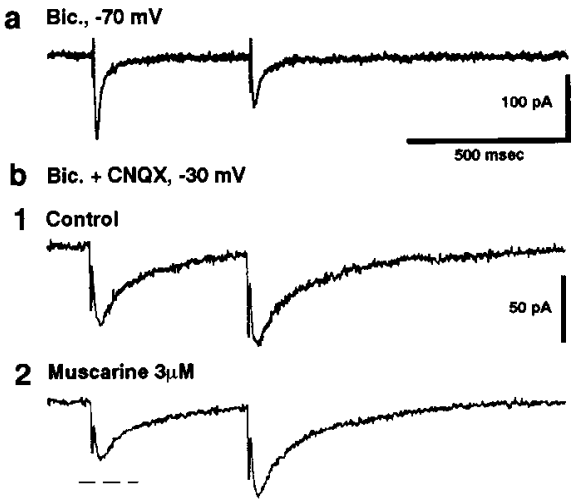

3 Wash out

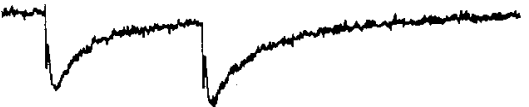

4 Pirenzepine $1.4 \mu \mathrm{M}$

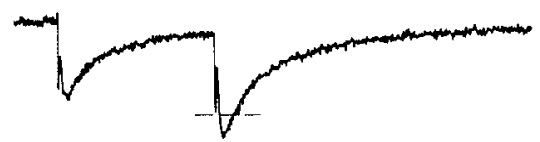

Figure 11. PPD and PPF of slow EPSCs. $A_{u}$, The respective traces of the PPD at ISIs of $0.2,0.5$, and 1 sec at $-30 \mathrm{mV}$ in the presence of bicuculline $(20 \mu \mathrm{M})$ and CNQX $(20 \mu \mathrm{M})$ were superimposed. Note that PPD was not prominent at $0.2 \mathrm{sec}$ ISI. $A_{b}$, Baclofen (5 $\left.\mu \mathrm{M}\right)$ reduced the first and second responses at respective ISIs markedly, but resulted in a PPF at $0.2 \mathrm{sec}$ ISI. $A_{c}$, Plottings of PPD ratio against ISIs with a logarithmic scale. The PPDs obtained in the control condition (partly shown in $A_{a}$ ) and during baclofen (partly shown in $A_{b}$ ) were represented by open and solid circles, respectively. Error bars at 0.2 and $0.5 \mathrm{sec}$ ISIs represent SD values $(n=6$ trials). Each open and solid circle represents the mean value of three to six trials. Note that baclofen attenuated the early phase of the PPD and revealed PPF at ISIs shorter than 1 sec, leaving the late phase of the PPD (ISIs $>3 \mathrm{sec}$ ) almost unchanged, $B_{\omega}$, a PPD of fast EPSCs at $0.5 \mathrm{sec}$ ISI at $-70 \mathrm{mV}$ induced in a layer V pyramidal cell in the presence of bicuculline. $B_{b}$, not PPD but a slight PPF induced at $-30 \mathrm{mV}$ in the same cell as in $B a$ during applying CNQX (20 $\mu \mathrm{M}$ ) in addition to bicuculline $(20 \mu \mathrm{M})$. Under these conditions, muscarine $(3 \mu \mathrm{M})$ reduced the first response without marked effect on the second response (2). Washout of muscarine restored the first response (3). Pirenzepine $(1.4 \mu \mathrm{M})$ increased the second response without marked effect on the first response (4). Note a different behavior between fast and slow EPSCs in response to PS in the same neuron.

of early baclofen-sensitive and late muscarine-sensitive components. Thirdly, even when PPF or no PPD was seen in either fast or slow EPSC's, the other displayed a prominent PPD in the same neurons. These observations suggest that a part of glutamatergic fibers likely arising from layer II/III terminate predominantly onto NMDA receptors in single pyramidal cells, and receive distinct presynaptic control through at least the muscarinic receptors.

With respect to the selective activation of NMDA receptors, it has been reported that EPSPs that were almost selectively mediated by the activity of NMDA receptors were induced in layer II/III pyramidal cells in rat frontal cortex (Thomson, 1986). Recently, it has also been reported that NMDA currents were almost selectively induced in layer $\mathrm{V}$ pyramidal cells by caged transmitter activated locally on apical dendrites using scanning laser photostimulation (Dalva and Katz, 1994), although the dominance of NMDA responses may change with development (Agmon and O'Dowd, 1992).

The time course of baclofen and muscarine-sensitive PPD of slow EPSCs was slower than that of baclofen-sensitive PPD of fast EPSCs. The time course of muscarinic EPSPs has been reported to be several tens of seconds in CA1 pyramidal neurons (Benardo and Prince, 1982; Cole and Nicoll, 1984; Madison et al., 1987) whereas that of GABA $_{B}$ IPSPs has been reported to be about one second (Alger and Nicoll, 1982; Connors et al., 1988; McCormick, 1989; Kang et al., 1994). Thus, the activation of postsynaptic muscarinic receptors occurs over a much longer time course than that of postsynaptic $\mathrm{GABA}_{\mathrm{B}}$ receptors. The difference in the time course of the PPD between fast and slow EPSC's observed in the present study may reflect a difference in the temporal profile of activity of $\mathrm{GABA}_{\mathrm{B}}$ and muscarinic receptors, which are probably located on the presynaptic terminals.

\section{Origin of the PPD of fast and slow EPSCS}

The presynaptic mechanism of the PPD of monosynaptic IPSPs or IPSCs is well established (Davies et al., 1990; Forsythe and Clements, 1990; Davies and Collingridge, 1993; Fukuda et al., 1993; Mott et al., 1993). It has also been reported that polysynaptic IPSCs displayed a similar PPD (Mott et al., 1993). In the present study, if EPSCs had been induced polysynaptically, the PPD might have been brought about by the postsynaptic inhibition of excitatory interneurons in the polysynaptic pathway. If some excitatory interneurons, which possessed $\mathrm{GABA}_{\mathrm{B}}$ and/or muscarinic receptors, had mediated glutamatergic EPSCs, it is possible for the second response to have been reduced by the postsynaptic inhibition of these interneurons through the activation of postsynaptic $\mathrm{GABA}_{\mathrm{B}}$ and/or muscarinic receptors by the first stimulation. If this was the case, the latency and the time-to-peak of the second response would have increased with an increase in the degree of PPD, because the generation of action potential in excitatory interneurons by the second stimulus could have been delayed by the increasing inhibition. However, the latency and the time course of the second fast and slow EPSCs remained almost unchanged in spite of the depression of 
the second responses as described in the Results (e.g., Figs. 3, 4). In addition, the time course of the PPD of fast and slow EPSCs was much longer than that of GABA 1 IPSPs $(<1 \mathrm{sec}$; Alger and Nicoll, 1982; Connors et al., 1988; Tseng and Haberly, 1988; McCormick, 1989; Kang et al., 1994). These observations would clearly indicate that the PPD is distinct from postsynaptic inhibition in the di- or polysynaptic pathways. On the other hand, if the PPD of EPSCs was caused by a reduction of driving potential due to an inadequate space clamp or by a reduction of the numbers of available receptors resulting from the residual occupation of receptors during the decay time course of the first response, then the reduction of the second response would have occurred in response to only those PS with ISIs shorter than the duration of the first EPSCs. However, the PPD was much less prominent at those shorter ISIs than at longer ISIs and the time course of the PPD was much longer than the duration of EPSCs (Fig. 3). Therefore, it is unlikely that the PPD is caused by reduction of either the driving potential or the numbers of available receptors. Nevertheless, this possibility can not be discarded entirely at short ISIs (<0.2 sec; Mori et al., 1994).

\section{Involvement of polysynaptic EPSCs}

Fast and slow EPSCs may involve di- or polysynaptic components. Slow EPSCs were induced in the presence of CNQX. As it has been reported that di-synaptic IPSPs induced in pyramidal cells of rat frontal cortex were completely abolished by applying $20 \mu \mathrm{M}$ CNQX (Kawaguchi, 1992), di- or polysynaptic transmission would not be likely to occur in the presence of CNQX. Even so, it might be possible that a bath application of bicuculline may have enhanced isolated NMDA components to a degree where NMDA components alone mediated disynaptic transmission. As is evident from the presence of a long tail on the EPSC recorded at $60 \mathrm{mV}$ in the presence of bicuculline (Figs. $1 A$, $10 A_{a-c}$ ), bicuculline might have enhanced di- or polysynaptic transmission. However, CNQX abolished this tail current almost completely (Fig. 1B). Usually, PPD of slow EPSCs was examined after confirming that no appreciable EPSCs were induced at $-70 \mathrm{mV}$ in the presence of bicuculline and CNQX. Therefore, polysynaptic transmission enhanced by bicuculline may have been suppressed largely by CNQX, and slow EPSCs may be induced monosynaptically. In contrast, for fast EPSCs, an involvement of polysynaptic components can not be discarded entirely. However, as shown in Figure $10, A_{b}$ and $A_{c}$, APV abolished large and long tail currents without any appreciable changes in the peak amplitude of fast EPSCs and in the degree of PPD. This suggests that the PPD of fast EPSCs is independent of the presence of late polysynaptic components, although they may have been enhanced largely by NMDA components in the presence of bicuculline. This notion was further supported by the observation that fast "EPSCs," which were contaminated with depolarizing IPSCs evoked in $145 \mathrm{~mm}$ CsCl-loaded cells at $-70 \mathrm{mV}$ in the absence of bicuculline, were reduced in amplitude but prolonged in the decay time course by an application of bicuculline without any significant changes in the PPD ratio of fast EPSCs (data not shown).

\section{Effects of baclofen and muscarine on fast and slow EPSCS}

Baclofen completely attenuated the PPD of fast EPSCs without reducing the second responses $(n=12)$. This suggests that the PPD of fast EPSCs was mediated entirely by the activity of $\mathrm{GABA}_{\mathrm{B}}$ receptors. However, effects of baclofen on the PPD of slow EPSCs were different from those on fast EPSCs. Baclofen largely attenuated the PPD of slow EPSCs in response to PS at $0.2 \mathrm{sec}$ ISI, by decreasing not only the first but also the second response (Fig. $7 A-C$ ). However, in the presence of muscarine, baclofen reduced the first response alone without reducing the second response appreciably at $0.2 \mathrm{sec}$ ISI (Fig. $8 A_{b}, A_{c}$ ). Furthermore, muscarine simultaneously decreased the first and second responses of slow EPSCs evoked at $0.2 \mathrm{sec}$ ISI (see Fig. $8 A_{a}, A_{b}$ ) with only a slight attenuation of the PPD (Fig. $8 B$ ). A simultaneous reduction of the first and second response at a certain ISI by baclofen (or muscarine) may indicate the presence of an additional component of PPD that is insensitive to baclofen (or muscarine).

A similar simultaneous reduction of the first and second IPSCs by baclofen leading to a marked attenuation of the PPD has been reported in synaptic connections between single cultured hippocampal neurons (Wilcox and Dichter, 1994). However, $\mathrm{GABA}_{\mathrm{B}}$ antagonists were not able to remove the PPD of IPSCs in the same study. Since GABAergic neurons are known to contain various transmitters, such as ACh, CC.K and NPY in addition to GABA (e.g., Kaneko et al., 1992), those transmitters may have been released simultaneously with GABA. If the action of these unknown transmitters causes a PPD that is also sensitive to baclofen, it would be impossible for $\mathrm{GABA}_{\mathrm{B}}$ antagonists to remove the PPD as has been observed in the previous studies (Yoon and Rothman, 1991; Wilcox and Dichter, 1994), although a bath application of baclofen should be able to attenuate the PPD.

\section{References}

Agmon A, O’Dowd D (1992) NMDA receptor-mediated currents are prominent in the thalamocortical synaptic response before maturation of inhibition. J Neurophysiol 68:345-349.

Alger BE, Nicoll RA (1982) Feed-forward dendritic inhibition in rat hippocampal pyramidal cells studied in vitro. J Physiol (Lond) 328: $105-123$.

Asanuma H, Rosen 1 (1973) Spread of mono- and polysynaptic connections within cats motor cortex. Exp Brain Res 16:507-520.

Benardo LS, Prince DA (1982) Ionic mechanisms of cholinergic excitation in mammalian hippocampal pyramidal cells. Brain Res 249 : $333-344$

Bowery NG, Hudson AL, Price GW (1987) GABA and GARA G $_{A}$ receptor site distribution in the rat central nervous system. Neuroscience 20:365-383.

Cole AE, Nicoll RA (1984) Characterization of a slow cholinergic postsynaptic potential recorded in vitro from rat hippocampal pyramidal cells. J Physiol (Lond) 352:173-188.

Colmers WF, Lukowiak K, Pittman Q (1988) Neuropeptide Y action in the rat hippocampal slice: site and mechanism of presynaptic inhibition. J Neurosci 8:3827-3837.

Connors BW, Malenka RC, Silva LR (1988) Two inhibitory postsynaptic potentials, and $\mathrm{GABA}_{A}$ and $\mathrm{GABA}_{\mathrm{B}}$ receptor-mediated responses in neocortex of rat. J Physiol (Lond) 406:443-468.

Dalva MB, Katz LC (1994) Functional NMDA receptors are preferentially located on apical dendrites of pyramidal neurons in ferret visual cortex. Soc Neurosci Abstr 20:349.13.

Davies $\mathrm{CH}$, Collingridge GL (1993) The physiological regulation of synaptic inhibition by $\mathrm{GABA}_{\mathrm{B}}$ autoreceptors in rat hippocampus. $\mathrm{J}$ Physiol (Lond) 472:245-265.

Davies CH, Davies SN, Collingridge GL (1990) Paired-pulse depression of monosynaptic GABA-mediated inhibitory postsynaptic responses in rat hippocampus. J Physiol (Lond) 424:513-531.

Forsythe ID, Clements JD (1990) Presynaptic glutamate receptors depress excitatory monosynaptic transmission between mouse hippocampal neurons. J Physiol (Lond) 429:1-16.

Fukuda A, Mody I, Prince DA (1993) Differential ontogenesis of presynaptic and postsynaptic $\mathrm{GABA}_{\mathrm{B}}$ inhihition in rat somatosensory cortex. J Neurophysiol 70:448-452.

Harrison NL (1990) On the presynaptic action of baclofen at inhibitory 
synapses between cultured rat hippocampal neurons. J Physiol (I ond) 422: $433-446$.

Hestrin S, Nicoll RA, Perkel DJ, Sah P (1990) Analysis of excitatory synaptic action in pyramidal cells using whole-cell recording from rat hippocampal slices J Physiol (Lond) 422:203-225.

Kaneko T, Nakaya Y, Mizuno N (1992) Paucity of glutaminase-immunoreactive nonpyramidal neurons in the rat cerebral cortex. J Comp Neurol 322:181-190.

Kang Y, Kaneko T, Ohishi H, Endo K, Araki T (1994) Spatiotemporally differential inhibition of pyramidal cells in the cat motor cortex. J Neurophysiol 71:280-293.

Kawaguchi Y (1992) Receptor subtypes involved in callosally-induced postsynaptic potentials in rat frontal agranular cortex in vitro. Exp Brain Res 88:3-40.

Mack BJ, Smith PA, Colmers W F (1993) 4-aminopiridine (4- $\Lambda$ P) does not affect presynaptic inhibition by muscarine in rat hippocampal CA1 in vitro. Soc Neurosci Abstr 19:625.1.

Madison DV, Lancaster B, Nicoll RA (1987) Voltage clamp analysis of cholinergic action in the hippocampus. J Neurosci 7:733-741.

McCormick DA (1989) GABA as an inhibitory neurotransmitter in human cerebral cortex. J Neurophysiol 62:1018-1027.

Mori A, Takahashi T, Miyashita Y, Kasai H (1994) Two distinct glutamatergic synaptic inputs to striatal medium spiny neurons of neonatal rats and paired-pulse depression. J Physiol (Lond) 476:217-228.

Mott DD, Xie CW, Wilson WA, Swarzwelder HS, Lewis DV (1993) $\mathrm{GABA}_{\mathrm{B}}$ autoreceptors mediate activity-dependent disinhibition and enhance signal transmission in the dentate gyrus. I Neurophysiol 69: 674-691.

Scholz KP, Miller RJ (1991) $\mathrm{GABA}_{\mathrm{B}}$ receptor-mediated inhibition of $\mathrm{Ca}^{2+}$ currents and synaptic transmission in cultured rat hippocampal neurons. J Physiol (Lond) 444:669--686.

Sheridan RD, Sutor B (1990) Presynaptic M, muscarinic cholinoceptors mediate inhibition of excitatory synaptic transmission in the hippocampus in vitro. Neurosci Lett 108:273-278.

Sugita S, Johnson SW, North RA (1992) Synaptic inputs GABA and $\mathrm{GABA}_{\mathrm{B}}$ originate from discrete afferent neurons. Neurosci Lett 29: $243-248$.

Thomson AM (1986) A magnesium-sensitive post-synaptic potential in rat cerebral cortex resembles neuronal responses to $N$-methylaspartate. J Physiol (Lond) 370:531-549.

Tseng GF, Haberly LB (1988) Characterization of synaptically mediated fast and slow inhibitory processes in piriform cortex in an in vitro slice preparation. J Neurophysiol 59:1352-1376.

Verhage M. McMahon HT, Ghijsen WEJM, Boomsma F, Scholten G, Wiegant VM, Nicholls DG (1991) Differential release of amino acids, neuropeptides, and catecholamines from isolated nerve terminals. Neuron 6:517-524

Wilcox KS, Dichter MA (1994) Paired pulse depression in cultured hippocampal neurons is due to a presynaptic mechanism independent of $\mathrm{GABA}_{\mathrm{B}}$ autoreceptor activation. J Neurosci 14:1775-1788.

Yoon KW, Rothman SM (1991) The modulation of rat hippocampal synaptic conductances by baclofen and gamma-aminobutyric acid. J Physiol (Lond) 442:377-390. 